ARTICLE

https://doi.org/10.1038/s41467-020-17625-3

\title{
High-throughput gas separation by flexible metal-organic frameworks with fast gating and thermal management capabilities
}

\author{
Shotaro Hiraide (i) ${ }^{1}$, Yuta Sakanaka ${ }^{1}$, Hiroshi Kajiro ${ }^{2}$, Shogo Kawaguchi $\mathbb{D}^{3}{ }^{3}$, Minoru T. Miyahara (i) ${ }^{1 凶} \&$
} Hideki Tanaka (1D 4 四

Establishing new energy-saving systems for gas separation using porous materials is indispensable for ensuring a sustainable future. Herein, we show that ELM-11 $\left(\left[\mathrm{Cu}\left(\mathrm{BF}_{4}\right)_{2}\left(4,4^{\prime}-\right.\right.\right.$ bipyridine $\left.{ }_{2}\right]_{n}$ ), a member of flexible metal-organic frameworks (MOFs), exhibits rapid responsiveness to a gas feed and an 'intrinsic thermal management' capability originating from a structural deformation upon gas adsorption (gate-opening). These two characteristics are suitable for developing a pressure vacuum swing adsorption (PVSA) system with rapid operations. A combined experimental and theoretical study reveals that ELM-11 enables the high-throughput separation of $\mathrm{CO}_{2}$ from a $\mathrm{CO}_{2} / \mathrm{CH}_{4}$ gas mixture through adiabatic operations, which are extreme conditions in rapid pressure vacuum swing adsorption. We also propose an operational solution to the 'slipping-off' problem, which is that the flexible MOFs cannot adsorb target molecules when the partial pressure of the target gas decreases below the gate-opening pressure. Furthermore, the superiority of our proposed system over conventional systems is demonstrated.

\footnotetext{
${ }^{1}$ Department of Chemical Engineering, Kyoto University, Nishikyo, Kyoto 615-8510, Japan. ${ }^{2}$ Nippon Steel Corporation, 20-1 Shintomi, Futtsu, Chiba 293-8511, Japan. ${ }^{3}$ Japan Synchrotron Radiation Research Institute (JASRI), SPring-8, 1-1-1 Kouto, Sayo, Hyogo 679-5198, Japan. ${ }^{4}$ Research Initiative for SupraMaterials (RISM), Shinshu University, 4-17-1 Wakasato, Nagano 380-8553, Japan. ${ }^{\circledR}$ email: miyahara@cheme.kyoto-u.ac.jp; htanaka@shinshu-u.ac.jp
} 
alf of the USA's industrial energy is consumed in separation processes, among which $49 \%$ of separation costs are for distillation ${ }^{1}$. To ensure a sustainable future, it is necessary to establish new-energy-saving purification systems, such as gas permeation with membranes and gas adsorption with porous materials. Pressure vacuum swing adsorption (PVSA) and temperature swing adsorption (TSA) processes are much more energy efficient than distillation. However, it is difficult for these techniques to achieve high-throughput separation, which requires system enlargement, because they cause pressure loss and crushing of adsorbents at the bottom of the adsorption column. One potential solution to this problem is to rapidly operate a PVSA process to increase the flow rate of the gas without enlarging the system size. This technique, so-called rapid PVSA, is currently widely investigated and recognized as a possible strategy $^{2-4}$. However, the rapid PVSA process is also limited in that the short-term cycle makes the system more adiabatic; thus, the generation of heat of adsorption and resulting amount of the decrease in adsorption is more serious than in the case of the normal PVSA process. The coexistence of adsorbents and phase change materials as latent heat storage mediums in a column may solve this problem ${ }^{5}$, though such a coexistence requires system enlargement. Therefore, to achieve a high-throughput separation system, innovative adsorption materials that exhibit a large loading capacity, high selectivity, and minimal heat of adsorption are required. Such ground-breaking materials must have completely different characteristics than conventional materials because high affinity and low heat of adsorption are essentially conflicting.

For a dozen years, metal-organic frameworks (MOFs) have been extensively studied as promising porous materials, as their designable framework structures can provide desirable adsorption properties. Moreover, flexible MOFs have attracted great attention as a result of their peculiar "gate-opening" and "breathing" behaviour, which is a structural transition phenomenon induced by guest adsorption ${ }^{6-11}$. The gate-opening and breathing effects induce stepwise change in the amount adsorbed at a specific gas pressure, which engenders larger working capacities and higher selectivities than the conventional adsorbents do. This is schematically illustrated in Fig. 1a,b; therein, the classical Langmuirtype adsorption isotherm is shown. Furthermore, it has been recently reported that flexible MOFs possess "intrinsic thermal management" capabilities ${ }^{12,13}$. Namely, the exothermic heat associated with guest adsorption is partially offset by the endothermic expansion of the host framework during gate-opening. The opposite phenomenon occurs during gate-closing based on the relationship between the endothermic heat of desorption of the guest and the exothermic shrinkage of the host. These effects are not observed for conventional adsorbents with rigid frameworks, but they are desired features for the rapid PVSA process: resulting from the suppressed heating impact owing to the adsorption and cooling from desorption, the $\mathrm{CO}_{2}$ loading and working capacities of flexible MOFs during the rapid PVSA cycle can be much larger than those of conventional adsorbents (Fig. 1c).

To demonstrate that the flexible MOFs can be breakthrough materials for actual high-throughput separation processes, the following three issues require clarification. The first involves the time constant for the gate-opening; the duration of the feed operation of a rapid PVSA process should be short (i.e., a few tens of seconds). Namely, the gate-opening accompanying the structural deformation of the host framework must respond quickly to the gas feed and be accomplished considerably faster than the cycle time. Second, the separation properties must be retained for operations under non-isothermal conditions. To the best of our knowledge, the intrinsic thermal management capability of flexible MOFs for such a condition has not been discussed. The third issue involves solving the "slipping-off" phenomenon of the flexible MOFs; flexible MOFs cannot adsorb guest molecules when the partial pressure of the guest in a gas mixture flowing in an adsorption column decreases below its specific gate-opening pressure. This has not been recognized as a major challenge in the development of gas separation systems using flexible MOFs, as it was first reported by Horike et al. ${ }^{14}$. However, this is a crucial matter when considering the separation for a binary mixture $(\alpha$ and $\beta$ ): using a flexible MOF that exhibits gate-opening only for component $\alpha$, the pure component $\beta$ cannot be obtained at the outlet of an adsorption column because of the slipping-off of component $\alpha$ from the adsorption column (Fig. 1d).

Here, we focus on ELM-11 $\left(\left[\mathrm{Cu}\left(\mathrm{BF}_{4}\right)_{2}\left(4,4^{\prime} \text {-bipyridine }\right)_{2}\right]_{\mathrm{n}}\right)^{15,16}$, which has a flexible framework and shows a typical gate adsorption for $\mathrm{CO}_{2}$ at ambient temperatures, as an adsorbent for $\mathrm{CO}_{2} / \mathrm{CH}_{4}$ gas mixture separation. The separation of $\mathrm{CO}_{2} / \mathrm{CH}_{4}$ gas mixtures such as those found in natural gas and landfill gas have gathered attention in the field of carbon capture and storage technologies ${ }^{17-19}$. First, we reveal that the gate-opening/closing behaviour of ELM-11 for $\mathrm{CO}_{2}$ is sufficiently fast in response to the increasing/decreasing of $\mathrm{CO}_{2}$ gas pressure by time-resolved in situ synchrotron X-ray powder diffraction (XRPD) measurements. Second, we compare the $\mathrm{CO}_{2}$ separation characteristics (uptake, selectivity, working capacity, and regenerability) of ELM11 and HKUST-1 ([Cu $\left.\left.(1,3,5 \text {-benzenetricarboxylate })_{2}\right]_{\mathrm{n}}\right)^{20}$ having a rigid framework that was reported as the most promising adsorbent for landfill gas separation ${ }^{17}$. We then illustrate the superiority of ELM-11, assuming a rapid PVSA process for landfill gas separation $\left(\mathrm{CO}_{2}: \mathrm{CH}_{4}=50: 50\right)$ composed of the following four elementary steps: (i) pressurization and adsorption of an equimolar $\mathrm{CO}_{2} / \mathrm{CH}_{4}$ mixture at $500 \mathrm{kPa}$, (ii) depressurization and rinsing with pure $\mathrm{CO}_{2}$ at $250 \mathrm{kPa}$, (iii) desorption at $15 \mathrm{kPa}$, and (iv) purging with pure $\mathrm{CH}_{4}$ at $15 \mathrm{kPa}$. We finally show that the issue of the slipping-off phenomenon can be solved by improving the adsorption column from an operational point of view, and we demonstrate that our proposed rapid PVSA process using flexible MOFs is an advanced adsorption system for $\mathrm{CO}_{2}$ separation.

\section{Results}

Pressure-aided fast gating of the flexible MOF. We investigated the rate of structural transition on gating of ELM-11 by timeresolved in situ synchrotron XRPD measurements. Figure 2a,b show that the structural transition of ELM-11 started immediately after the introduction of $\mathrm{CO}_{2}$ at $40.8 \mathrm{kPa}$ and $273 \mathrm{~K}$, and was accomplished in $\sim 10 \mathrm{~s}$. We also confirmed that ELM-11 accommodating $\mathrm{CO}_{2}$ responded quickly to the decrease in gas pressure at $273 \mathrm{~K}$ : the structural transition was completed in $5 \mathrm{~s}$ when the $\mathrm{CO}_{2}$ pressure was decreased at the rate of $2.4 \mathrm{kPa} \mathrm{s}^{-1}$ (Fig. 2c,d, and Supplementary Fig. 1). Time development of the fraction of the open phase by introducing $\sim 41 \mathrm{kPa}$ of $\mathrm{CO}_{2}$ at 273,264 , and $241 \mathrm{~K}$ is shown in Fig. 2e, and that of the closed phase is shown in Fig. 2f; it can be seen that the rate of phase transition increases as the temperature decreases under the same $\mathrm{CO}_{2}$ pressure. We also investigated the dependence of the rate of phase transition on the pressure at $227 \mathrm{~K}$, as shown in Fig. $2 \mathrm{~g}$,h, and found that the rate of structural transition increased with increasing $\mathrm{CO}_{2}$ pressure, and the phase transition was completed within a few seconds at the highest gas pressure. Furthermore, these data were found to obey the Kolmogorov-Johnson-Mehl-Avrami (KJMA) equation ${ }^{21,22}$, as drawn with solid lines in Fig. 2e-h. The obtained parameters are summarized in Supplementary Table 1. The KJMA parameters for the open and closed phases under the same experimental conditions are in good agreement within the fitting errors, 


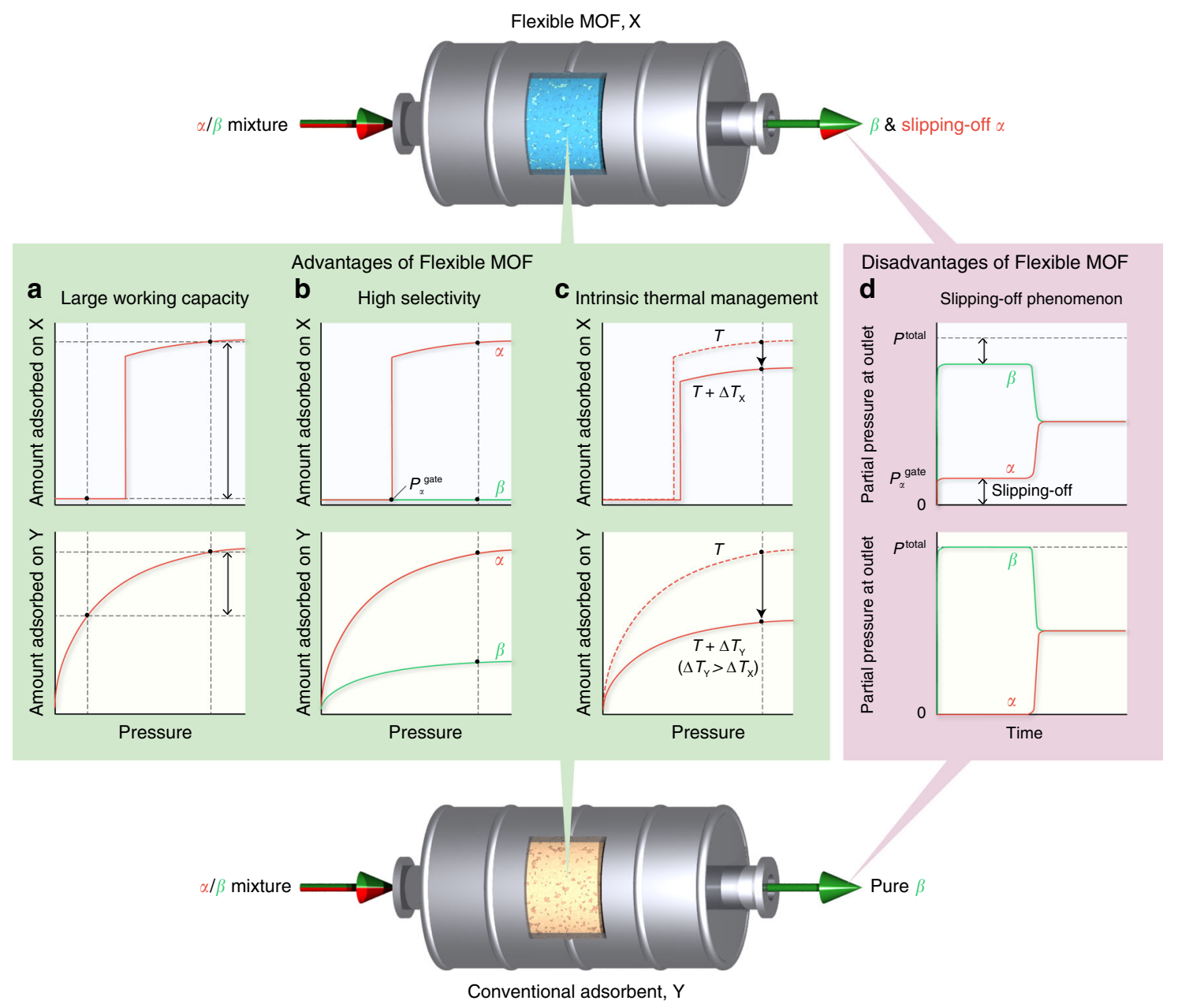

Fig. 1 Advantages and disadvantages of flexible metal-organic frameworks (MOFs). a Stepwise change in the amount adsorbed due to the gate-opening of the flexible MOF, $\mathrm{X}$, can provide a larger working capacity when the same pressure swing is considered for the flexible MOF and the conventional adsorbent, Y. b For a gas mixture adsorption (components $\alpha$ and $\beta$ ), the flexible MOF can give higher selectivity for component $\alpha$ than the conventional adsorbent can give, because the gate-opening is a kind of molecular recognition; in this case, the flexible MOF can only accommodate component $\alpha$ and shows gate-opening. $\mathbf{c}$ When an adiabatic gas adsorption is considered, the temperature rise of the system for the flexible $M O F, \Delta T_{x}$, is smaller than that for the conventional adsorbent, $\Delta T_{Y}$, and the resulting decrease in the adsorption amount can be suppressed because of the smaller net heat of adsorption of the flexible MOF owing to its intrinsic thermal management capability. $\mathbf{d}$ The flexible MOF cannot adsorb component $\alpha$ when the partial pressure of $\alpha$ in a gas mixture decreases below the inherent gate-opening pressure of the flexible MOF, $P_{\alpha}$ gate. Thus, a pure effluent gas (component $\beta$ ) cannot be obtained at the end of the adsorption column ("slipping-off" phenomenon).

although the errors for the closed phase are mostly larger than those for the open phase because of the lower intensity of the 020 reflection of the closed phase. Figure $2 \mathrm{i}$ shows the relation between the rate constant of the KJMA equation and the pressure difference, $P-P$ gate, where $P$ is the $\mathrm{CO}_{2}$ pressure introduced into the glass capillary with ELM-11 and Pgate is the gate-opening pressure. We found that a characteristic curve in proportion to $P$ - Pgate could be drawn for all the rate constants of the open phase investigated. The constant of proportionality was determined to be $12.0 \pm 0.5 \mathrm{~s}^{-1 / n} \mathrm{MPa}^{-1}$ by least-squares fitting of Eq. (3). This suggests that the rate constant only depends on the $\mathrm{CO}_{2}$ gas pressure and the temperature, which controls the gate-opening pressure, and that the gate-opening rate is amplified by the $\mathrm{CO}_{2}$ pressure exerted on ELM-11. This equation tells us that it takes only $1.5 \mathrm{~s}$ for ELM- 11 to achieve $95 \%$ structural transition when $\mathrm{CO}_{2}$ gas of $250 \mathrm{kPa}$ is introduced at $298 \mathrm{~K}$. This feature is particularly suitable for the rapid PVSA proposed in the later section.

It is also worth noting that the exponents of the KJMA equation, $n$, obtained from all the data for the open phase were $1.2-1.3$, which indicates the quasi-one-dimensional growth of the open phase of ELM-1 $11^{21}$. This is indeed consistent with the mechanism of gate-opening predicted in the previous study: ${ }^{23}$ one-dimensional channels composed of the stacked twodimensional square grid layers are formed in ELM-11 once the interlayer distance is increased, and simultaneously, the $\mathrm{CO}_{2}$ molecules penetrate through the one-dimensional channels (Supplementary Fig. 2), i.e. the formation of the open phase encapsulating $\mathrm{CO}_{2}$ proceeds along the one-dimensional direction.

Adsorption properties under isothermal conditions. Figure 3a shows the experimental single-component adsorption isotherms for $\mathrm{CO}_{2}$ and $\mathrm{CH}_{4}$ on HKUST-1 at $298 \mathrm{~K}$; the data were taken from the Virial-Langmuir equations experimentally determined by Chowdhury et al. ${ }^{24}$. The total and component adsorption isotherms of an equimolar $\mathrm{CO}_{2} / \mathrm{CH}_{4}$ mixture on HKUST-1 at $298 \mathrm{~K}$, and the selectivity of $\mathrm{CO}_{2}$ over $\mathrm{CH}_{4}$, were evaluated by the ideal adsorbed solution theory ${ }^{25}$ using the experimentally obtained single-component adsorption isotherms; the obtained data are shown in Fig. 3b. Figure $3 c$ depicts our experimentally 

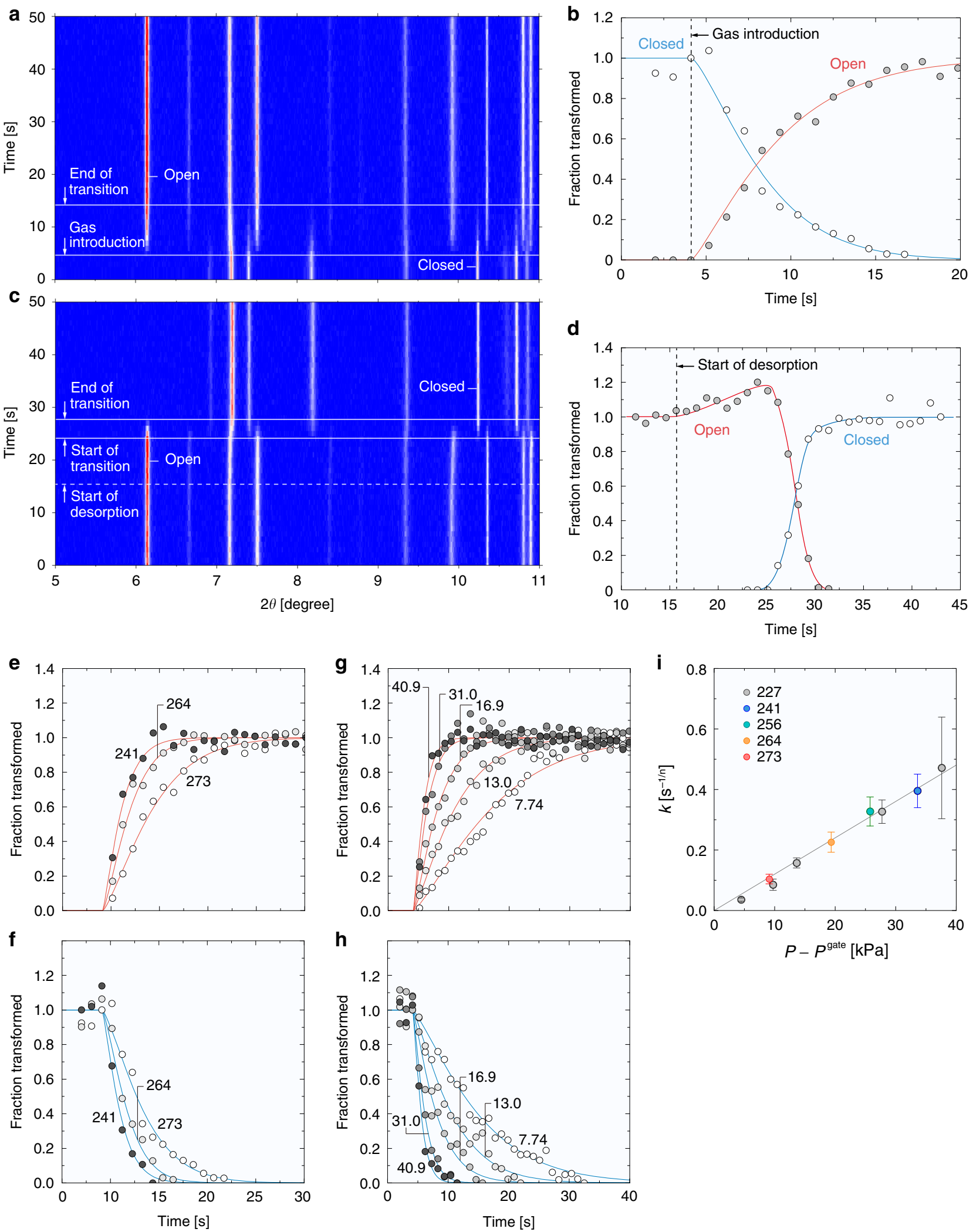

obtained single-component adsorption isotherms for $\mathrm{CO}_{2}$ and $\mathrm{CH}_{4}$ on ELM-11 at $298 \mathrm{~K}$ together with their theoretical adsorption isotherms obtained by grand canonical Monte Carlo (GCMC) simulations using the quenched open framework structure of ELM-11, which was determined by the Rietveld method for pure $\mathrm{CO}_{2}$ gas adsorption at $298 \mathrm{~K}^{23,26}$. The plateau of the simulated adsorption isotherm for $\mathrm{CO}_{2}$ on the quenched open framework was in good agreement with that of the experimentally obtained one for $\mathrm{CO}_{2}$ on ELM-11, demonstrating the validity of our GCMC simulations. The fictitious GCMC isotherm for $\mathrm{CH}_{4}$ on the quenched open framework shows low adsorption, even though the framework has voids to accommodate $\mathrm{CH}_{4}$ molecules, 
Fig. 2 Time-resolved in situ synchrotron X-ray powder diffraction (XRPD) measurements. a Colour map of XRPD patterns for $\mathrm{CO}_{2}$ adsorption on ELM-11 at $273 \mathrm{~K}$ and a constant pressure of $40.8 \mathrm{kPa}$. b Normalized peak intensities (fractions of the phase transformed) from the 002 reflection at $6.1^{\circ}$ for the open phase and the 020 reflection at $10.2^{\circ}$ for the closed phase shown in $\mathbf{a}$. The two solid lines after $4.15 \mathrm{~s}$ were obtained by fitting of the Kolmogorov-Johnson-Mehl-Avrami (KJMA) equation. c Colour map of XRPD patterns for $\mathrm{CO}_{2}$ desorption at $273 \mathrm{~K}$ during pressure depression from 100 to $3.8 \mathrm{kPa}$ (the change in $\mathrm{CO}_{2}$ pressure is shown in Supplementary Fig. 1). d Fractions of the phase transformed from the 002 reflection for the open phase and the 020 reflection for the closed phase shown in $\mathbf{c}$. e Fractions of the phase transformed for the open phase and $\mathbf{f}$ for the closed phase at 40.8 $\mathrm{kPa}$ and $241 \mathrm{~K}$, at $41.0 \mathrm{kPa}$ and $264 \mathrm{~K}$, and at $40.8 \mathrm{kPa}$ and $273 \mathrm{~K}$. The numbers in $\mathbf{e}$ and $\mathbf{f}$ denote the temperature. $\mathbf{g}$ Fractions of the phase transformed for the open phase and $\mathbf{h}$ for the closed phase at $227 \mathrm{~K}$ as a function of the $\mathrm{CO}_{2}$ pressure. The numbers in $\mathbf{g}$ and $\mathbf{h}$ denote the $\mathrm{CO}_{2}$ gas pressure in $\mathrm{kPa}$ introduced. The curves after $4.15 \mathrm{~s}$ in $\mathbf{e}-\mathbf{h}$ were obtained by fitting of the KJMA equation. i Relationship between the rate coefficients and the pressure difference between the $\mathrm{CO}_{2}$ gas pressure, $P$, and the gate-opening pressure, $P$ gate. The error bar represents the standard deviation of the value obtained using the least-square fitting of the KJMA equation to the experimental data ( $n \geq 3, n$ : number of experimental points used for fitting). The rate coefficients used in this plot are those for the open phase tabulated in Supplementary Table 1. The solid line in $\mathbf{i}$ was obtained from the least-squares fitting of Eq. (3).

which is due to the weak solid-fluid interactions. In contrast, the experimental isotherm of $\mathrm{CH}_{4}$ shows no adsorption, which is because the affinity of $\mathrm{CH}_{4}$ is too weak to pry open the framework of ELM-11. We also performed in situ XRPD measurements of ELM-11 in vacuo and after adsorption of $\mathrm{CO}_{2}$ gas $(50 \mathrm{kPa}), \mathrm{CH}_{4}$ gas $(50 \mathrm{kPa})$, and an equimolar mixture of $\mathrm{CO}_{2} / \mathrm{CH}_{4}$ gas $(94 \mathrm{kPa})$ at $273 \mathrm{~K}$, respectively, which are shown in Fig. 4a. The XRPD pattern of ELM-11 exposed to $\mathrm{CH}_{4}$ gas was the same as that in vacuo, and the XRPD pattern of ELM-11 after adsorption of the $\mathrm{CO}_{2} / \mathrm{CH}_{4}$ gas mixture perfectly coincided with that after gate adsorption of $\mathrm{CO}_{2}$. This strongly suggests that the open framework structure of ELM-11 after the adsorption of the equimolar $\mathrm{CO}_{2} / \mathrm{CH}_{4}$ gas mixture is the same as that after the adsorption of pure $\mathrm{CO}_{2}$. Hence, we computed the total and component adsorption isotherms of the equimolar $\mathrm{CO}_{2} / \mathrm{CH}_{4}$ gas mixture and the selectivity of $\mathrm{CO}_{2}$ over $\mathrm{CH}_{4}$ by GCMC simulations using the open framework structure of ELM-11 for pure $\mathrm{CO}_{2}$. The obtained results are shown in Fig. 3d.

The compatibility of the open framework structures of ELM-11 for pure $\mathrm{CO}_{2}$ adsorption and equimolar $\mathrm{CO}_{2} / \mathrm{CH}_{4}$ gas mixture adsorption can also provide insights into the slipping-off phenomenon of ELM-11. The gate-opening of ELM-11 under the flow of $\mathrm{CO}_{2} / \mathrm{CH}_{4}$ mixture gas should not occur when the $\mathrm{CO}_{2}$ partial pressure of mixture gas falls below the gate-opening pressure of ELM-11 for pure $\mathrm{CO}_{2}$ adsorption. Namely, the fraction of slipping-off $\mathrm{CO}_{2}$ in an effluent gas can be estimated as the ratio of the gate adsorption pressure for pure $\mathrm{CO}_{2}$ adsorption and the total gas pressure in the adsorption column. Indeed, by using our experimental gate-opening pressure of ELM-11 for pure $\mathrm{CO}_{2}$, we successfully predicted the effluent fraction of $\mathrm{CO}_{2}$ of the experimental breakthrough curve, as described in a later section.

The separation characteristics of HKUST-1 and ELM-11, evaluated by assuming that all steps of the PVSA process were operated under isothermal conditions at $298 \mathrm{~K}$, are shown in Fig. 3e. The $\mathrm{CO}_{2}$ selectivity, $S^{\text {ads }}$, of ELM-11 was 9.5 times higher than that of HKUST-1 (ELM-11: $S^{\text {ads }}=82.3$, HKUST-1: $S^{\text {ads }}=$ 8.67). Thus, the high $\mathrm{CO}_{2}$ selectivity of ELM-11 arises from the fact that the GCMC adsorption isotherms for the quenched open framework at low pressures $(<50 \mathrm{kPa})$ show an overwhelmingly high affinity for $\mathrm{CO}_{2}$ over $\mathrm{CH}_{4}$, compared with HKUST-1. There has been an argument that the gate adsorption does not necessarily lead to high adsorption selectivity because guest molecules with low affinity should be adsorbed on the host framework pried open by other guest molecules with high affinity; 27,28 however, this is not the case for ELM-11. Specifically, the adsorption amount of $\mathrm{CH}_{4}$ in the open framework is much less than that of $\mathrm{CO}_{2}$, as shown in Fig. 3c, even though the open framework of ELM-11 provides enough space for adsorption. This is because ELM-11 provides a purpose-built framework structure for $\mathrm{CO}_{2}$ in terms of size and intermolecular interactions as depicted in Fig. $4 \mathrm{~b}$. Owing to the large pore volume of
HKUST-1 (Fig. 4c), its $\mathrm{CO}_{2}$ uptake, $\mathrm{N}_{\mathrm{CO}_{2}}^{\mathrm{ads}}$, reached $9.08 \mathrm{mmol}$ $\mathrm{g}^{-1}$, which is 2.6 times the $\mathrm{CO}_{2}$ uptake of ELM-11. After the desorption process, the amount of adsorbed $\mathrm{CO}_{2}, \mathrm{~N}_{\mathrm{CO}}^{\text {des }}$, on HKUST-1 was $0.95 \mathrm{mmol} \mathrm{g}^{-1}$; hence, the $\mathrm{CO}_{2}$ working capacity of HKUST-1 decreased slightly to $\Delta N_{\mathrm{CO}_{2}}=8.13 \mathrm{mmol} \mathrm{g}{ }^{-1}$, which is still 2.3 times larger than that of ELM-11. The regenerability of ELM-11 (100\%) is superior to that of HKUST-1 (89.6\%), which arises from the fact that the amount of $\mathrm{CO}_{2}$ adsorbed on ELM-11 under desorption conditions $\left(\mathrm{CO}_{2}\right.$ pressure of $\left.15 \mathrm{kPa}\right)$ is zero, as a result of gate-closing. It is worth noting that if the open framework structure of ELM-11 is rigid and does not transform to the closed state, the $\mathrm{CO}_{2}$ adsorption isotherm during the desorption process must be type I (depicted by the red dashed line in Fig. 3c) and the $\Delta N_{\mathrm{CO}_{2}}$ value is only $0.96 \mathrm{mmol} \mathrm{g}^{-1}$, which corresponds to a regenerability of $27 \%$. In other words, for rigid adsorbents, the factors to improve regenerability and selectivity are essentially contradictory. In contrast, flexible MOFs can provide both perfect regenerability and high selectivity as long as the gate-opening and gate-closing pressures are compatible with the operating conditions of the PVSA process.

Adsorption properties under adiabatic conditions. We evaluated the "effective adsorption properties" of HKUST-1 and ELM-11 through adiabatic separation operations, which are extreme conditions in the rapid PVSA process: the values were obtained by considering the negative effects of temperature rise/ drop caused by heats of adsorption/desorption under adiabatic conditions. In this case, all of the heat generated by guest adsorption is consumed to increase the system temperature. Namely, the changes in adsorption amount and temperature in response to the pressure swing are determined such that the heat generated by adsorption is commensurate with the heat required to change the system temperature. For simplicity, the specific heat of gas can be ignored because it is much smaller than that of the adsorbent. Figure 5 a depicts the heats of adsorption for HKUST-1 as a function of temperature, represented as isobars for the equimolar $\mathrm{CO}_{2} / \mathrm{CH}_{4}$ mixture at $500 \mathrm{kPa}$, pure $\mathrm{CO}_{2}$ at $250 \mathrm{kPa}$, pure $\mathrm{CO}_{2}$ at $15 \mathrm{kPa}$, and pure $\mathrm{CH}_{4}$ at $15 \mathrm{kPa}$, corresponding to the operating pressures used for the rapid PVSA process (see also Supplementary Fig. 3). The heats of adsorption and specific heat of HKUST-1 were taken from the experimental data reported by Chowdhury et al..$^{24}$, Kloutse et al. ${ }^{29}$, and $\mathrm{Mu}$ et $\mathrm{al}^{30}$. The green plane in Fig. 5a represents the adiabatic operating plane calculated by integrating the specific heat of HKUST-1 with respect to temperature. Starting from point a, the intersection point of the green plane and yellow line $(298 \mathrm{~K})$, we considered performing adiabatic pressurization and adsorption with the equimolar $\mathrm{CO}_{2} /$ $\mathrm{CH}_{4}$ mixture at $500 \mathrm{kPa}$. The state should move from point a to the intersection of the red line and the green plane (point $\mathbf{b}$ ), because the heat released by adsorption and the heat absorbed by 

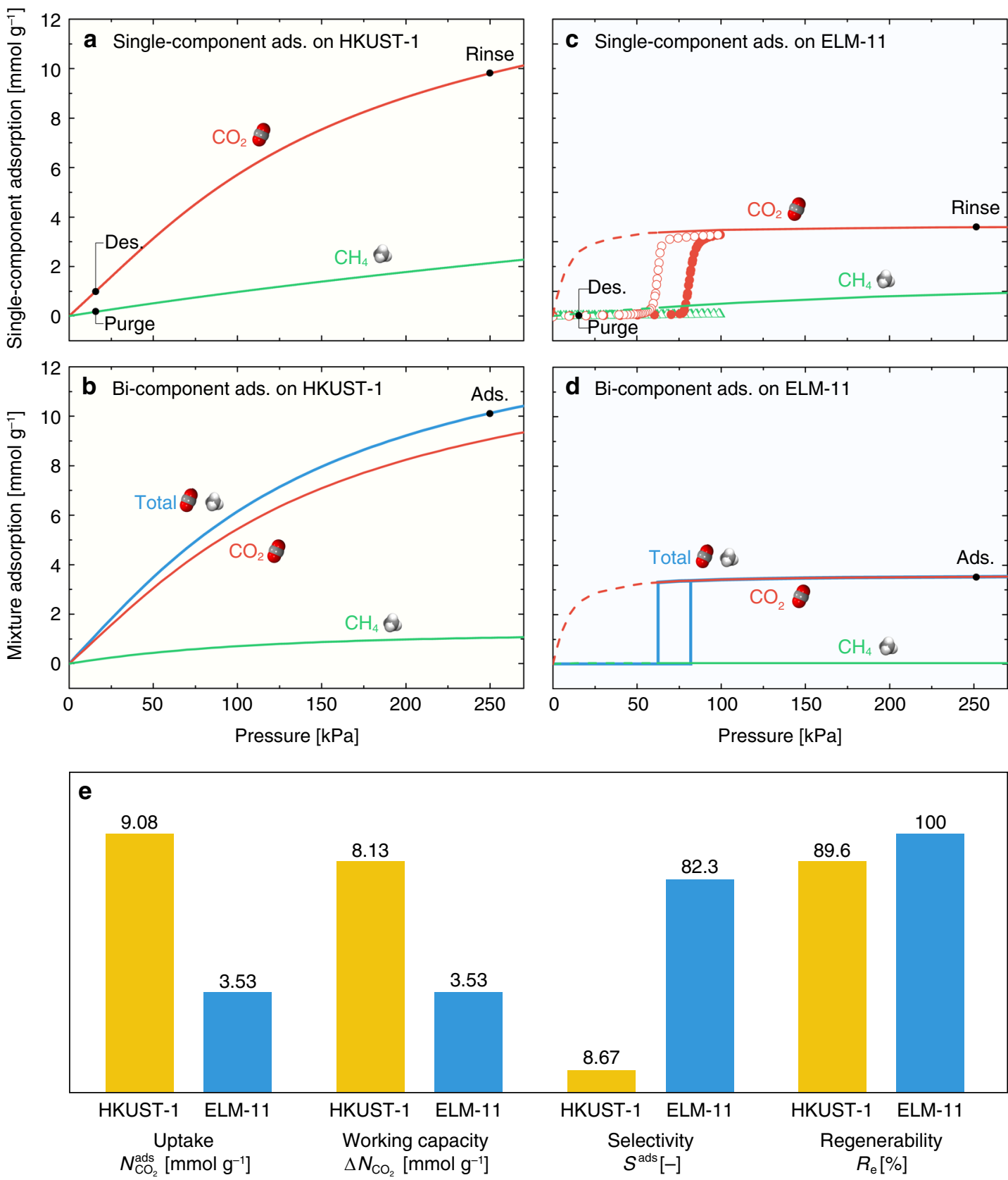

Fig. 3 Adsorption properties of HKUST-1 and ELM-11 under isothermal conditions. Single-component adsorption isotherms of $\mathrm{CO}_{2}$ and $\mathrm{CH}_{4}$ at $298 \mathrm{~K}$ on a HKUST-1 from the experimentally determined Virial-Langmuir equations ${ }^{24}$ and $\mathbf{c}$ ELM-11 (filled symbols: experimental adsorption data, open symbols: experimental desorption data, lines: adsorption data simulated by grand canonical Monte Carlo (GCMC)). Total and component adsorption isotherms of an equimolar mixture of $\mathrm{CO}_{2}$ and $\mathrm{CH}_{4}$ at $298 \mathrm{~K}$ for $\mathbf{b}$ HKUST-1 evaluated by the ideal adsorbed solution theory 25 and $\mathbf{d}$ ELM- 11 simulated by GCMC. The abscissae of $\mathbf{b}$ and $\mathbf{d}$ correspond to the partial pressures of $\mathrm{CO}_{2}$. Black filled circles represent the points at which the corresponding pressures were applied in the four elementary steps of the rapid pressure vacuum swing adsorption (PVSA) process. e $\mathrm{CO}_{2}$ separation characteristics of HKUST-1 and ELM- 11 assuming PVSA under isothermal conditions at $298 \mathrm{~K}$.

the adsorbent are equal at point $\mathbf{b}$. This means that the temperature of HKUST-1 changes from 298 to $370 \mathrm{~K}$ during the adiabatic pressurization and adsorption process. If we perform adiabatic depressurization and rinsing with pure $\mathrm{CO}_{2}$ at $250 \mathrm{kPa}$, the state moves to point $\mathbf{c}(366 \mathrm{~K})$, where the purple line and the green plane intersect. The adiabatic desorption of $\mathrm{CO}_{2}$ from 250 to $15 \mathrm{kPa}$ results in a significant decrease in the system temperature, as indicated by point $\mathbf{d}(313 \mathrm{~K})$. Finally, the state moves back to point a on adiabatic purging of $\mathrm{CO}_{2}$ with a flow of a pure $\mathrm{CH}_{4}$ gas at $15 \mathrm{kPa}$. The adsorption amounts of $\mathrm{CO}_{2}$ and $\mathrm{CH}_{4}$ on HKUST-1 at corresponding points $\mathbf{a}-\mathbf{d}$ are listed in Table 1.
To evaluate the adsorption properties of ELM-11 under adiabatic conditions, the temperature dependences of the enthalpy change of guest $-\Delta H^{\text {guest }}$, the net heat $q^{\text {net }}$, and the intrinsic thermal management capability $e$ were evaluated. At $298 \mathrm{~K}$, the exothermic heat $\Delta H^{\text {guest }}$ during the adsorption of the equimolar $\mathrm{CO}_{2} / \mathrm{CH}_{4}$ gas mixture at $500 \mathrm{kPa}$ was $135.3 \mathrm{Jg}^{-1}$; however, on considering the endothermic heat consumed by the host expansion $\left(\Delta H^{\text {host }}=55.7 \mathrm{Jg}^{-1}\right)^{13}$, the net heat $q^{\text {net }}$ decreased to $79.6 \mathrm{Jg}^{-1}$, which means that $e=41.1 \%$ of the exothermic heat was offset. The $e$ values were always $\sim 40 \%$ over the temperature range of $248-335 \mathrm{~K}$ and showed a small 
a

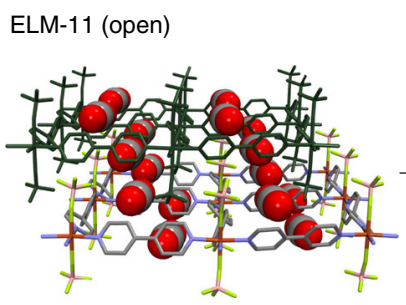

ELM-11 (closed)

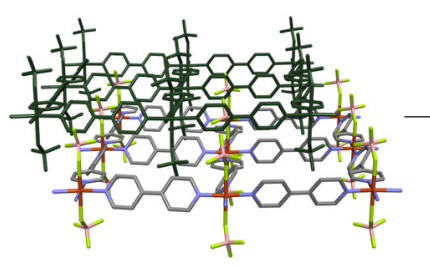

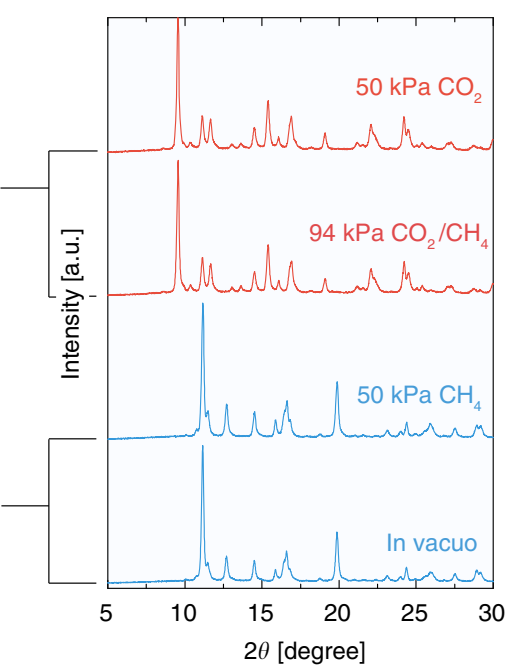

b

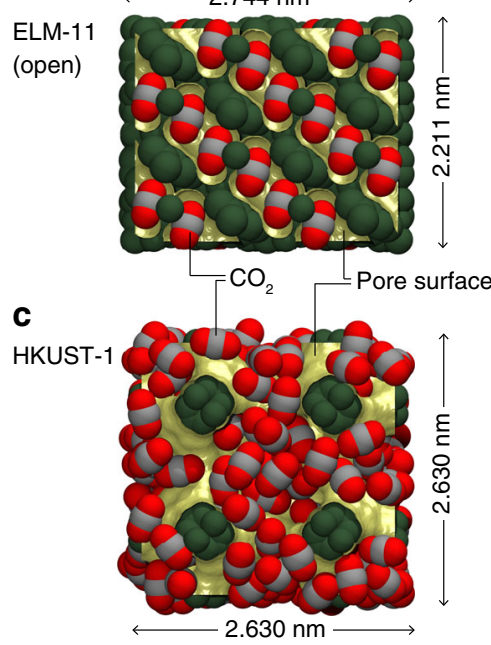

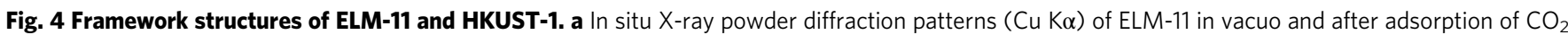
gas $(50 \mathrm{kPa}), \mathrm{CH}_{4}$ gas $(50 \mathrm{kPa})$, and an equimolar $\mathrm{CO}_{2} / \mathrm{CH}_{4}$ gas mixture $(94 \mathrm{kPa})$ at $273 \mathrm{~K}$ together with crystal structures of ELM-11 in closed and open states determined in our previous studies ${ }^{23,26}$. Pore structure and $\mathrm{CO}_{2}$ configuration of $\mathbf{b}$ ELM-11 and $\mathbf{c}$ HKUST-1.

dependence on the temperature, demonstrating the superior intrinsic thermal management capability of ELM-11 (Supplementary Fig. 4). Figure 5b shows the obtained heats of adsorption as a function of temperature for ELM-11. The isobars for the heats of adsorption for the equimolar $\mathrm{CO}_{2} / \mathrm{CH}_{4}$ mixture at $500 \mathrm{kPa}$ and pure $\mathrm{CO}_{2}$ at $250 \mathrm{kPa}$ show a sharp decrease at $335 \mathrm{~K}$ because of the gating of ELM-11. Starting from point $\mathbf{s}$ on the green plane at $298 \mathrm{~K}$, the state moves to point $\mathbf{t}(335 \mathrm{~K})$ on adiabatic pressurization and adsorption of the equimolar $\mathrm{CO}_{2} /$ $\mathrm{CH}_{4}$ mixture at $500 \mathrm{kPa}$. The green plane divides the perpendicular segment of the red line at $335 \mathrm{~K}$ into two parts, suggesting that $54 \%$ of ELM-11 undergoes gate adsorption (Supplementary Note 1). The state moves to point $\mathbf{u}$ upon adiabatic depressurization and rinsing with pure $\mathrm{CO}_{2}$ at $250 \mathrm{kPa}$; however, this process does not affect the system temperature. Adiabatic desorption of $\mathrm{CO}_{2}$ from 250 to $15 \mathrm{kPa}$ causes the system temperature to decrease to $298 \mathrm{~K}$ (point $\mathbf{v}$ ) and results in evacuation of all the $\mathrm{CO}_{2}$ molecules adsorbed on ELM-11. Therefore, purging of $\mathrm{CO}_{2}$ is not required for ELM-11 (point $\mathbf{v} \rightarrow$ point $\mathbf{s}$ ); this is an advantage of flexible MOFs showing gate adsorption. The adsorption amounts of $\mathrm{CO}_{2}$ and $\mathrm{CH}_{4}$ on ELM-11 at corresponding points $\mathbf{s}-\mathbf{v}$ are also listed in Table 1 .

The four separation characteristics of HKUST-1 and ELM-11 under adiabatic conditions are depicted in Fig. 5c together with those under isothermal conditions. Three data sets are classified in accordance with the "starting temperature", which should be set for point a for HKUST-1 and point $\mathbf{s}$ for ELM-11. If we set the starting temperature at $298 \mathrm{~K}$, the $\mathrm{CO}_{2}$ uptake of HKUST-1 significantly decreases to $2.00 \mathrm{mmol} \mathrm{g}^{-1}$ in contrast to $9.08 \mathrm{mmol}$ $\mathrm{g}^{-1}$ obtained for adsorption under isothermal conditions at $298 \mathrm{~K}$, becoming comparable with that of ELM-11 (1.68 mmol $\mathrm{g}^{-1}$ ) for adiabatic adsorption. The $\mathrm{CO}_{2}$ selectivity, $S^{\text {ads }}$, also decreases for both HKUST-1 and ELM-11 because of the temperature increase of the system $(\Delta T=71.5 \mathrm{~K}$ for HKUST-1 and $\Delta T=36.5 \mathrm{~K}$ for ELM-11, Table 1); however, the $S^{\text {ads }}$ value of ELM-11 still remains large. Furthermore, the $\mathrm{CO}_{2}$ working capacity of ELM-11 (1.68 $\left.\mathrm{mmol} \mathrm{g}^{-1}\right)$ surpasses the record of HKUST-1 (1.41 $\left.\mathrm{mmol} \mathrm{g}^{-1}\right)$.

The decrease in the starting temperature below $283 \mathrm{~K}$ can improve the $\mathrm{CO}_{2}$ uptake and working capacity of ELM-11, and all the separation characteristics of ELM-11 were found to be superior to those of HKUST-1 (Fig. 5c). This should be possible because the cyclic steady state of the PVSA process can be controlled by varying the initial temperature of the adsorption column $^{31}$. Fig. $5 d$ replots Fig. $5 b$ together with the heat balance curves assuming the starting temperatures of 283 and $263 \mathrm{~K}$. The PVSA cycle becomes $\mathbf{s}^{\prime} \rightarrow \mathbf{t}^{\prime} \rightarrow \mathbf{u}^{\prime} \rightarrow \mathbf{v}^{\prime} \rightarrow \mathbf{s}^{\prime}$ by setting the starting temperature as $283 \mathrm{~K}$ and crossing the perpendicular segment of the red line at point $\mathbf{t}^{\prime}$. The intersection point $\mathbf{t}^{\prime}$, at a higher heat of adsorption than point $\mathbf{t}$, refers to the increase in the ratio of ELM-11 undergoing gate adsorption, wherein the $\mathrm{CO}_{2}$ uptake of ELM-11 is improved (Fig. 5e). If we can further lower the starting temperature to $263 \mathrm{~K}$, the heat balance curve passes through the top of the perpendicular segment of the red line, and $100 \%$ of ELM-11 becomes available. This results in significant improvements in the $\mathrm{CO}_{2}$ uptake and working capacity of ELM-11. The starting temperature of $263 \mathrm{~K}$ may seem relatively low; however, some reports have shown that the temperature of adsorption columns attains values below $273 \mathrm{~K}$ in the cyclic steady state ${ }^{32,33}$. It should be also noted that, assuming that the system is completely adiabatic, the additional cost of cooling is unnecessary once the system cools down to the starting temperature and the cyclic steady state is established; hence, for a partially heatinsulated PVSA system, only a small amount of energy would be required for cooling to maintain the cyclic steady state.

In comparing the adsorption properties under the isothermal conditions and the adiabatic conditions for each adsorbent (Fig. 5c), the adsorption properties of ELM-11 are almost unaffected by the adsorption conditions, except for the $\mathrm{CO}_{2}$ selectivity. This fact suggests that flexible MOFs with the intrinsic thermal management capability are effective for improving the efficiency of the rapid PVSA system.

Strategy for preventing the slipping-off problem. ELM-11 can exhibit superior performance in the rapid PVSA system for landfill gas separation, as described in the previous section; however, pure $\mathrm{CH}_{4}$ gas cannot be obtained from the system unless the slipping-off problem is solved. To show it and demonstrate our strategy for preventing the slipping-off problem, we measured the breakthrough curve of $\mathrm{CO}_{2}$ on ELM-11 using the two systems shown in Fig. 6a,b. 
a

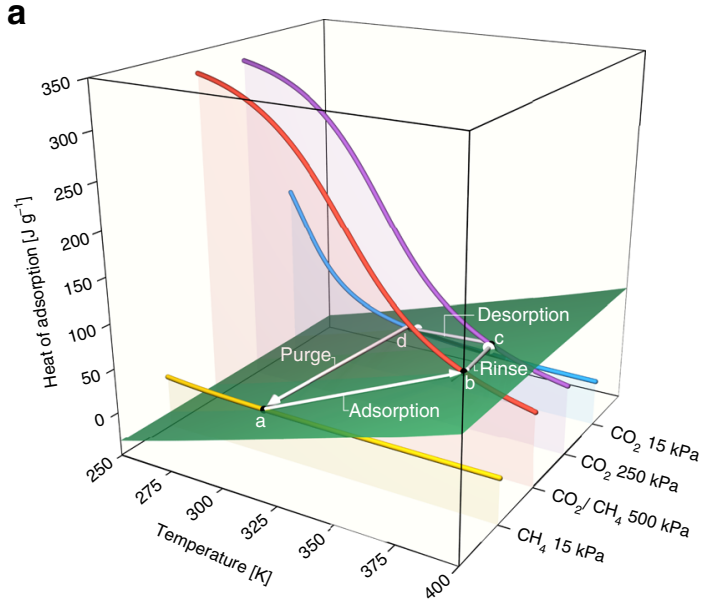

b

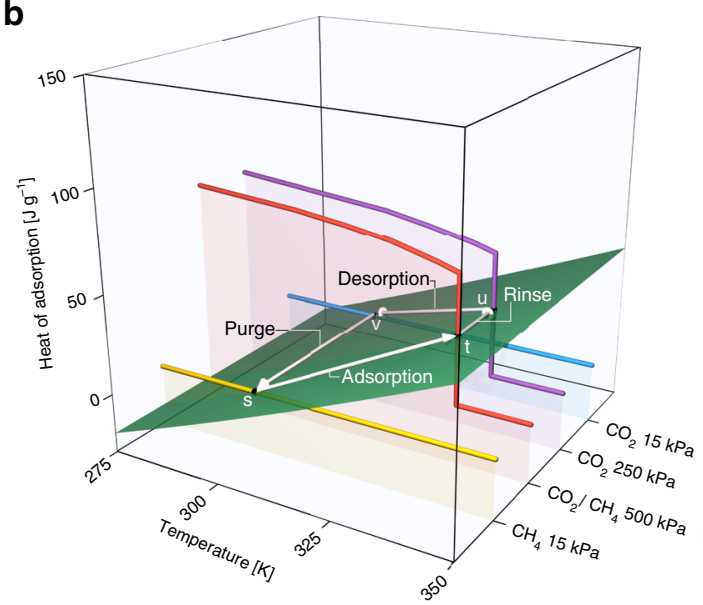

d

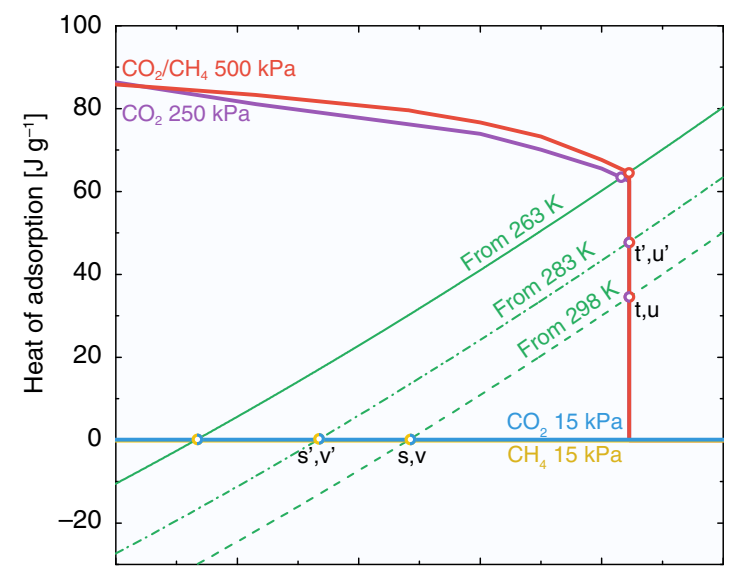

e

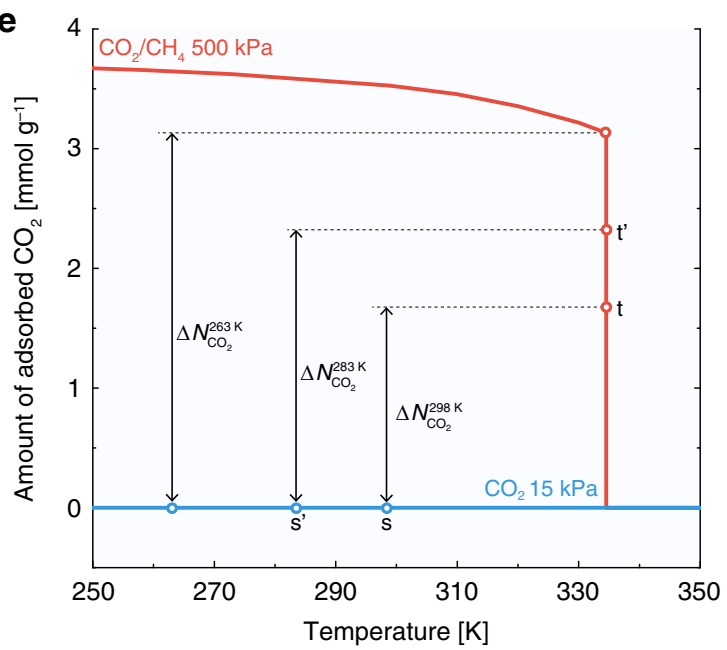

C

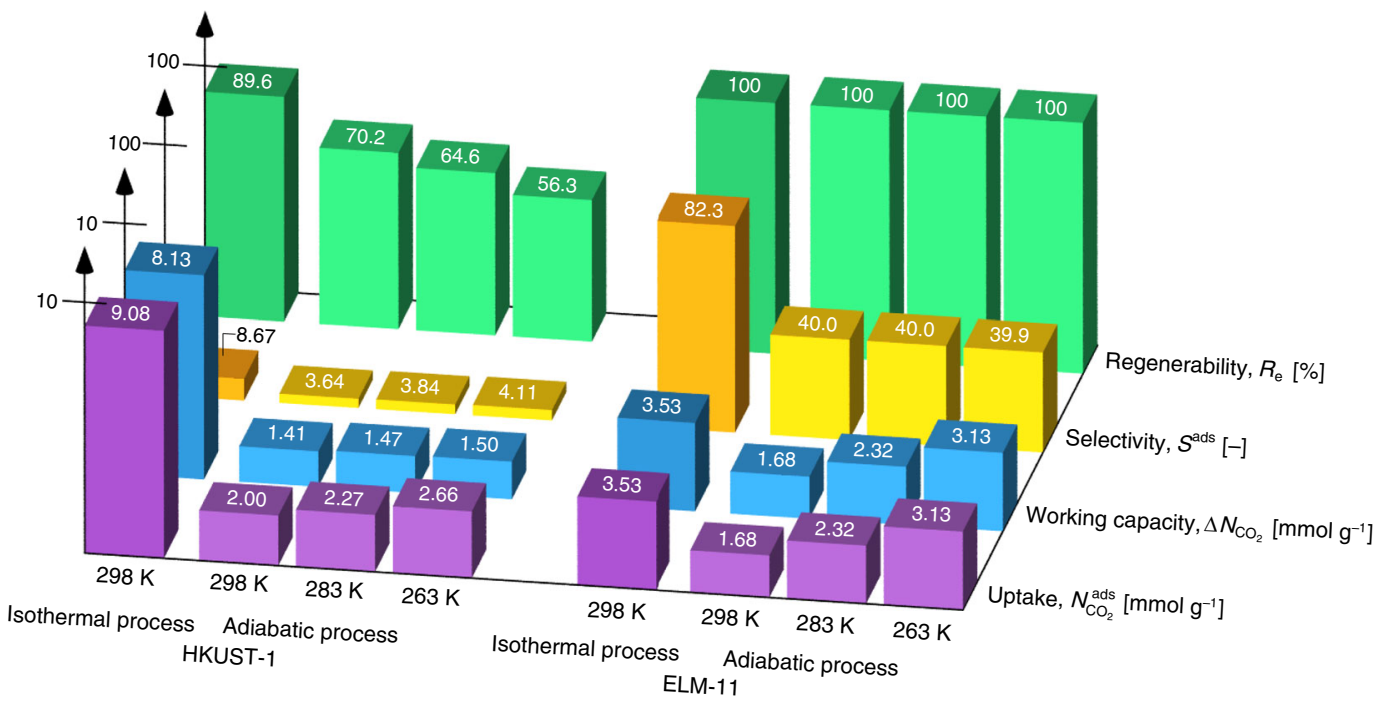

Fig. 5 Adsorption properties of HKUST-1 and ELM-11 under adiabatic conditions. Temperature dependence of heat of adsorption for a HKUST-1 and b ELM-11. Red line: adsorption of an equimolar $\mathrm{CO}_{2} / \mathrm{CH}_{4}$ gas mixture at $500 \mathrm{kPa}$, purple line: pure $\mathrm{CO}_{2}$ adsorption at $250 \mathrm{kPa}$, blue line: pure $\mathrm{CO}_{2}$ adsorption at $15 \mathrm{kPa}$, and yellow line: pure $\mathrm{CH}_{4}$ adsorption at $15 \mathrm{kPa}$. The green plane shows the heat required to change the temperature of the host framework. White arrows represent the four adiabatic operating processes of rapid pressure vacuum swing adsorption (PVSA). The starting temperature was set as $298 \mathrm{~K}$. c CO 2 separation characteristics of HKUST-1 and ELM-11 for PVSA assuming the adiabatic operations and the starting temperatures of 298,283 , and $263 \mathrm{~K}$ together with those assuming isothermal operations at $298 \mathrm{~K}$. d Temperature dependence of net heat of adsorption for ELM-11 for adsorption of an equimolar $\mathrm{CO}_{2} / \mathrm{CH}_{4}$ gas mixture at $500 \mathrm{kPa}$ (red), pure $\mathrm{CO}_{2}$ at $250 \mathrm{kPa}$ (purple), pure $\mathrm{CO}_{2}$ at $15 \mathrm{kPa}$ (blue), and pure $\mathrm{CH}_{4}$ at $15 \mathrm{kPa}$ (yellow). Green lines are the heat balance curves when the adiabatic adsorption process starts from 298, 283, and $263 \mathrm{~K}$. e Temperature dependence of the amount of $\mathrm{CO}_{2}$ adsorbed on ELM-11 for an equimolar $\mathrm{CO}_{2} / \mathrm{CH}_{4}$ mixture at $500 \mathrm{kPa}$ (red) and that for pure $\mathrm{CO}_{2}$ at $15 \mathrm{kPa}$ (blue). 
An equimolar $\mathrm{CO}_{2} / \mathrm{CH}_{4}$ gas mixture at $200 \mathrm{kPa}$ was flowed through a column containing ELM-11 at $273 \mathrm{~K}$, which was previously heat-treated and purged with pure Ar (Fig. 6a), and the gas composition of the outlet flow from the column was determined using a quadrupole mass spectrometer. As shown in Fig. $6 \mathrm{c}$, the $\mathrm{CO}_{2}$ fraction of the outlet stream became 0.16 after extruding the preloaded $\mathrm{Ar} \sim 1.5 \mathrm{~min}$. This is the slipping-off phenomenon, and another step around $12 \mathrm{~min}$ comes from the

Table 1 Adsorbed amounts of $\mathrm{CO}_{2}$ and $\mathrm{CH}_{4}$ and temperatures at points $a-d$ and $s-v$ in Fig. $5 a, b$.

\begin{tabular}{|c|c|c|c|c|}
\hline Adsorbent & Operation (point) & $\begin{array}{l}N_{\mathrm{CO}_{2}} \\
\left(\mathrm{mmol} \mathrm{g}^{-1}\right)\end{array}$ & $\begin{array}{l}\mathrm{N}_{\mathrm{CH}_{4}} \\
\left(\mathrm{mmol} \mathrm{g}^{-1}\right)\end{array}$ & $T(K)$ \\
\hline \multirow[t]{4}{*}{ HKUST-1 } & Adsorption (b) & 2.00 & 0.55 & 370 \\
\hline & Rinsing (c) & 2.25 & 0 & 366 \\
\hline & Desorption (d) & 0.60 & 0 & 313 \\
\hline & Purging (a) & 0 & 0.16 & 298 \\
\hline \multirow[t]{4}{*}{ ELM-11 } & Adsorption (t) & 1.68 & 0.04 & 334 \\
\hline & Rinsing (u) & 1.79 & 0 & 334 \\
\hline & Desorption (v) & 0 & 0 & 298 \\
\hline & Purging (s) & 0 & 0 & 298 \\
\hline
\end{tabular}

essential breakthrough of ELM-11. The fraction of slipping-off $\mathrm{CO}_{2}$ obtained by the breakthrough experiment is in good agreement with $P^{\text {gate }} / P_{\mathrm{t}}=0.165$, where $P^{\text {gate }}=33.1 \mathrm{kPa}$ is the gate adsorption pressure for pure $\mathrm{CO}_{2}$ adsorption on ELM-11 at $273 \mathrm{~K}$, and $P_{\mathrm{t}}=200 \mathrm{kPa}$ is the total pressure of the feed gas. This result indicates that lowering the gate adsorption pressure and/or increasing the total pressure of the feed gas can reduce the molar percentage of slipping-off gas. In fact, Horike et al. performed breakthrough experiments for $\mathrm{CO}_{2} / \mathrm{CH}_{4}$ and $\mathrm{CO}_{2} / \mathrm{C}_{2} \mathrm{H}_{6}$ gas mixtures adsorbed on solid solutions of [ $\mathrm{Zn}(5$-nitroisophthalate) $\left(4,4^{\prime}\right.$-bipyridine $\left.)\right]_{\mathrm{n}}$ and $\left[\mathrm{Zn}(5\right.$-methoxyisophthalate $)\left(4,4^{\prime}\right.$-bipyridine) $]_{\mathrm{n}}$. Their results demonstrated that the gate-opening pressure and the fraction of slipping-off $\mathrm{CO}_{2}$ was reduced by controlling the ratio of 5-nitroisophthalate/5-methoxyisophthalate ${ }^{14}$. Although their method is effective, it is probably applicable to only a limited range of flexible MOFs. Moreover, reducing the gating pressure would undermine the large working capacity and perfect regenerability, which are advantages of the flexible MOFs. Although over-pressurization of the feed gas was also suggested by Sotomayor and Lastoskie ${ }^{34}$, this would consume considerable energy because, for example, to obtain pure $\mathrm{CH}_{4}$ gas $(99.9 \%)$, the total pressure of the feed gas should be increased to $2.08 \mathrm{MPa}$ by assuming the adsorption process for an equimolar $\mathrm{CO}_{2} / \mathrm{CH}_{4}$ gas mixture with the starting temperature of $263 \mathrm{~K}$. a

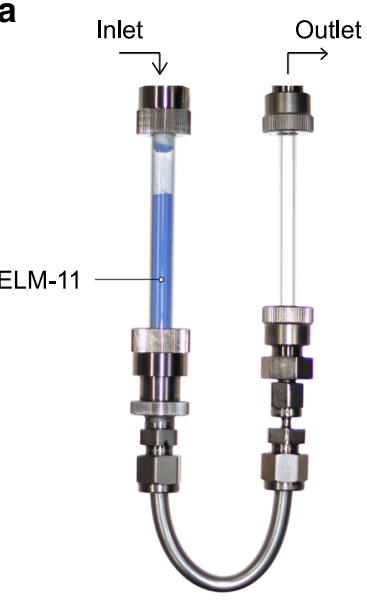

b

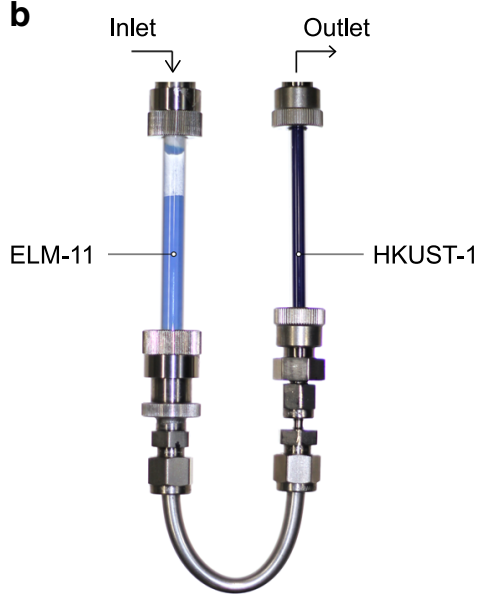

C

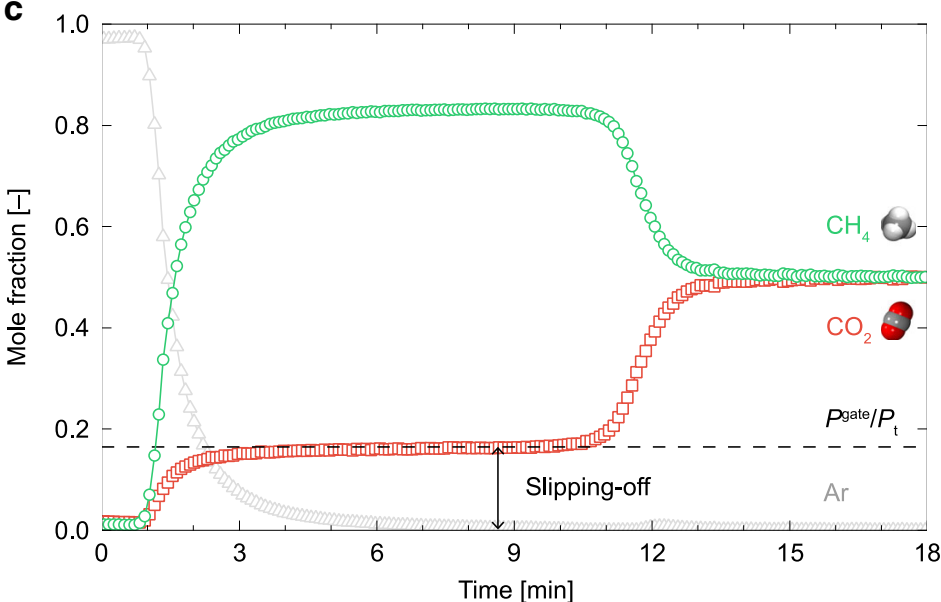

d

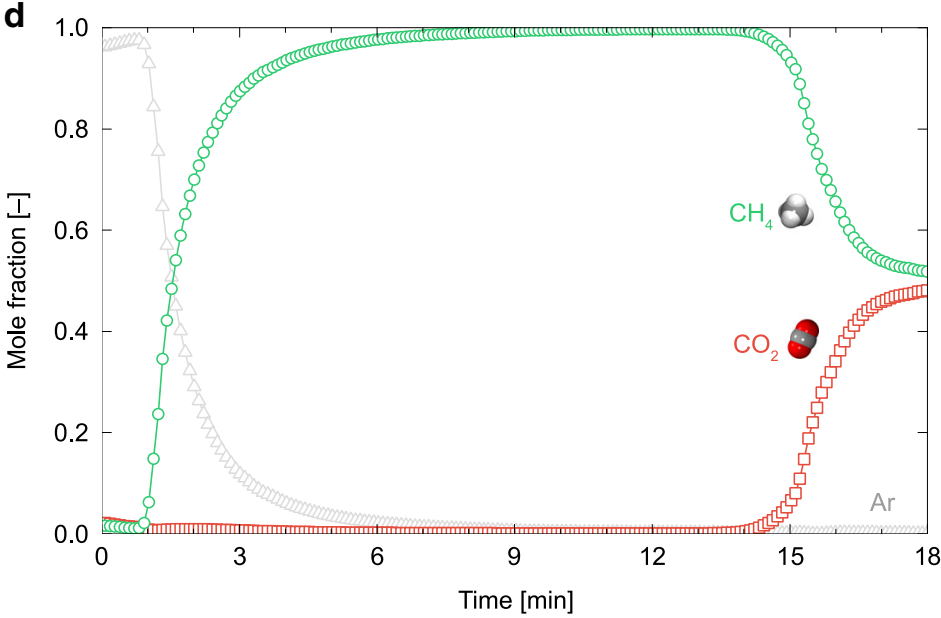

Fig. 6 Slipping-off problem and sequential-column system as a solution to this problem. Photographs of the column system used to measure the breakthrough curves: $\mathbf{a}$ a single-column system containing ELM-11 and $\mathbf{b}$ a sequential-column system containing ELM-11 and HKUST-1. c, d are breakthrough curves for an equimolar $\mathrm{CO}_{2} / \mathrm{CH}_{4}$ gas mixture in $\mathbf{a}$ and $\mathbf{b}$, respectively. The flow rate of the gas mixture was 20 sccm, and the adsorption columns were kept at $273 \mathrm{~K}$. The outlet pressure was maintained at $200 \mathrm{kPa}$. 

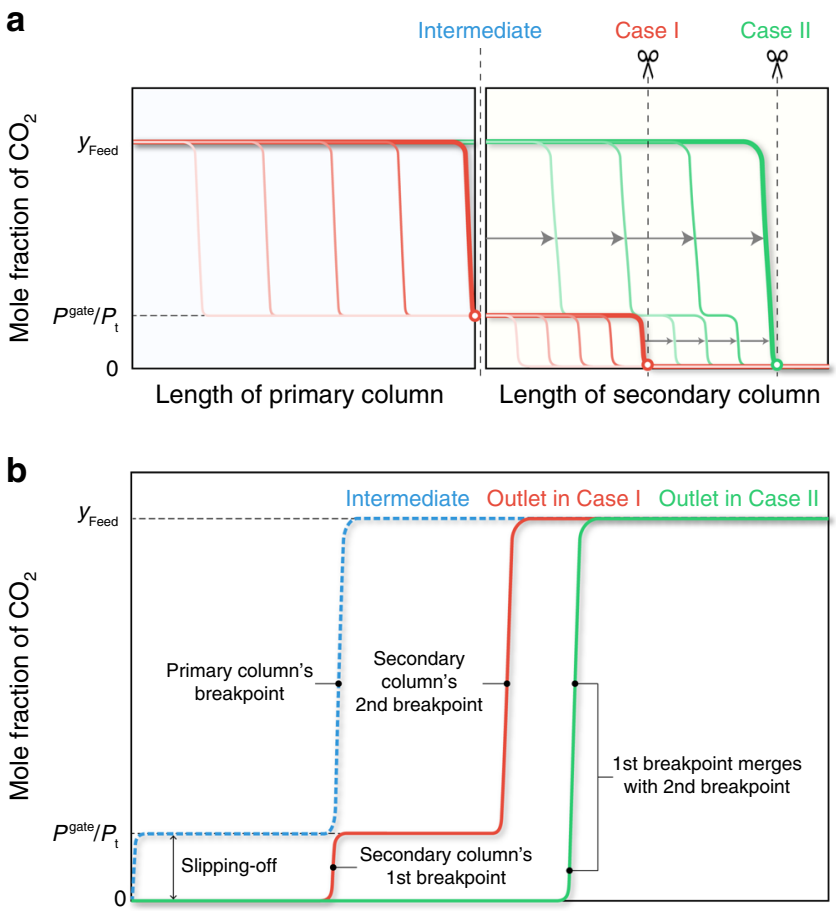

Time

Fig. 7 Development of $\mathrm{CO}_{2}$ fraction in gas stream passing through the sequential-column system. a Movement of the mass-transfer zone in the primary and secondary columns containing a flexible MOF and a Langmuirtype adsorbent, respectively, where red and green lines show the $\mathrm{CO}_{2}$ fraction in the stream in the columns before and after the primary column breaks through, respectively. b Breakthrough curves at the three positions indicated by dashed lines in $\mathbf{a}$, where "intermediate" is the outlet of the primary column, "case I" is the front of the mass-transfer zone in the secondary column when the primary column breaks through, and "case II" is the front of the mass-transfer zone when the first breakpoint just merges with the second one.

To prevent the $\mathrm{CO}_{2}$ slipping-off problem, we propose attaching a secondary column containing a conventional adsorbent that exhibits a Langmuir-type $\mathrm{CO}_{2}$ isotherm to a primary column filled with the flexible MOF. Although this system is similar to the one with multi-layered columns for separating a mixture of three or more components ${ }^{35}$, it is based on a new strategy using multiple items to improve the efficiency of the rapid PVSA system using the flexible MOF, as described in the following sections. To demonstrate the availability of our strategy, we set HKUST-1 in the secondary column downstream of the ELM-11 column (Fig. 6b), and we measured the breakthrough curve for the $\mathrm{CO}_{2} / \mathrm{CH}_{4}$ gas mixture at $200 \mathrm{kPa}$ and $273 \mathrm{~K}$. We successfully confirmed that no slipping-off $\mathrm{CO}_{2}$ was detected from the outlet of the secondary column, as shown in Fig. 6d. Note that to make the system cost-effective, the amount of conventional adsorbent for eliminating slipping-off $\mathrm{CO}_{2}$ can be determined, with two possible cases. Case I is to determine the amount of conventional adsorbent so that the secondary column's breakthrough owing to the slipping-off $\mathrm{CO}_{2}$ matches the primary column's breakthrough, as shown in Fig. 7a. Namely, the amount of conventional adsorbent should be the minimum quantity necessary for removing the slipping-off $\mathrm{CO}_{2}$, and in this case, the outlet flow from the secondary column exhibits a two-stage breakthrough, wherein the first breakpoint is related to the slipping-off $\mathrm{CO}_{2}$, and the second is related to the feed gas (Fig. 7b). However, it is clear that the conventional adsorbent installed in the secondary column, which was saturated by the slipping-off $\mathrm{CO}_{2}$, still has a redundant capacity to adsorb $\mathrm{CO}_{2}$. That is, after the $\mathrm{CO}_{2}$ fraction in the inlet flow for the secondary column was increased from the slipping-off concentration ( $P$ gate/ $\left.P_{\mathrm{t}}\right)$ to that of the feed flow $\left(y_{\text {Feed }}\right)$ owing to the primary column's breakthrough, the secondary column can be also available to remove $\mathrm{CO}_{2}$. Therefore, Case II should be designed to reduce the time lag between the first and second breakpoints to zero by installing a slightly larger amount of conventional adsorbent than that in Case I. This design is possible because the Langmuir-type adsorption isotherm of conventional adsorbent is convex upward (the slope of the isotherm decreases with an increasing concentration of $\mathrm{CO}_{2}$ ), and thus, the mass-transfer zone for reducing the $\mathrm{CO}_{2}$ fraction from $y_{\text {Feed }}$ to $P$ gate $/ P_{\mathrm{t}}$ moves faster than that for reducing the $\mathrm{CO}_{2}$ fraction from $P$ gate $/ P_{\mathrm{t}}$ to zero (Fig. 7a). The choice between Case I and Case II should depend on the operating conditions and the characteristics of the flexible and rigid adsorbents used.

Comparison between a conventional and our proposed system. To verify the effectiveness of our proposed system, we compared the performance of two rapid PVSA processes: a conventional system using a single column filled with HKUST-1 and our proposed system where ELM-11 and HKUST-1 are filled in the primary and secondary columns, respectively. These systems are schematically illustrated in Fig. 8a. We assumed that the adiabatic adsorption of equimolar $\mathrm{CO}_{2} / \mathrm{CH}_{4}$ mixture at $500 \mathrm{kPa}$ (starting temperature of $263 \mathrm{~K}$ ) was performed under the same conditions with the rapid PVSA process investigated in this study. We determined the column length and the molar flow rate of the feed gas required to obtain the same molar flow rate of $\mathrm{CH}_{4}$ (product gas), $F$, for both systems by conducting material balance calculations using the "effective adsorption properties" under adiabatic conditions obtained in the former section. Note that the basic concept of the calculation is analogous to the screening method for the PVSA systems developed by Maring and Webley, which can provide a good estimation ${ }^{36}$. The obtained results are shown in Fig. 8b. When we set the size of the column of the conventional system to $L$, our proposed system based on Case II only requires a primary column with a size of $0.224 L$ and a secondary column with a size of $0.082 L$ to accomplish the same molar flow rate of product gas, $F$. This means that our proposed system is, overall, $69 \%$ smaller than the conventional one, even though it consists of two columns. Moreover, the molar flow rate of the feed gas for our system $(2.39 F)$ was also found to be $62 \%$ less than that of the conventional one $(6.24 F)$. These results suggest that our proposed system, using the flexible MOFs, can be more efficient than the conventional system. In addition, if both systems are set to the same size, our system can process a much larger amount of gas and thus achieve a high-throughput $\mathrm{CO}_{2}$ separation. Note that the proposed system based on Case I is also superior to the conventional system, as demonstrated in detail in Supplementary Note 2.

\section{Discussion}

Time-resolved in situ synchrotron XRPD measurements revealed that the $\mathrm{CO}_{2}$ gate-opening of ELM-11 can be extremely fast when $P-P$ gate is large. This should be an inherent characteristics of ELM-11 originated from its framework structure because it has been reported that, conversely, other flexible MOFs exhibit slow transitions ${ }^{37}$. Moreover, it was found that ELM-11 accommodating $\mathrm{CO}_{2}$ responded quickly to the decrease in gas pressure; the gate-closing can be much faster than the gate-opening. This suggests that the desorption of $\mathrm{CO}_{2}$ is accelerated by the 


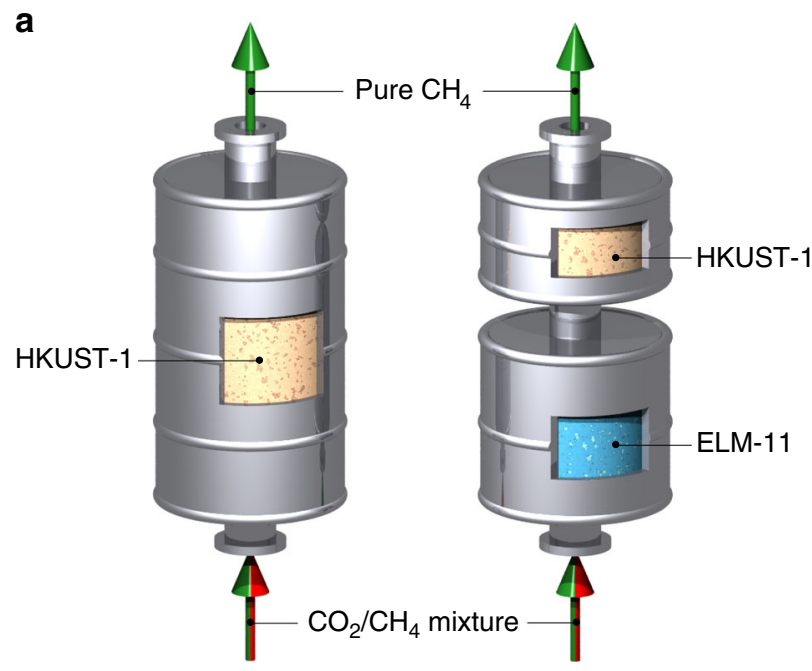

Conventional system

Proposed system

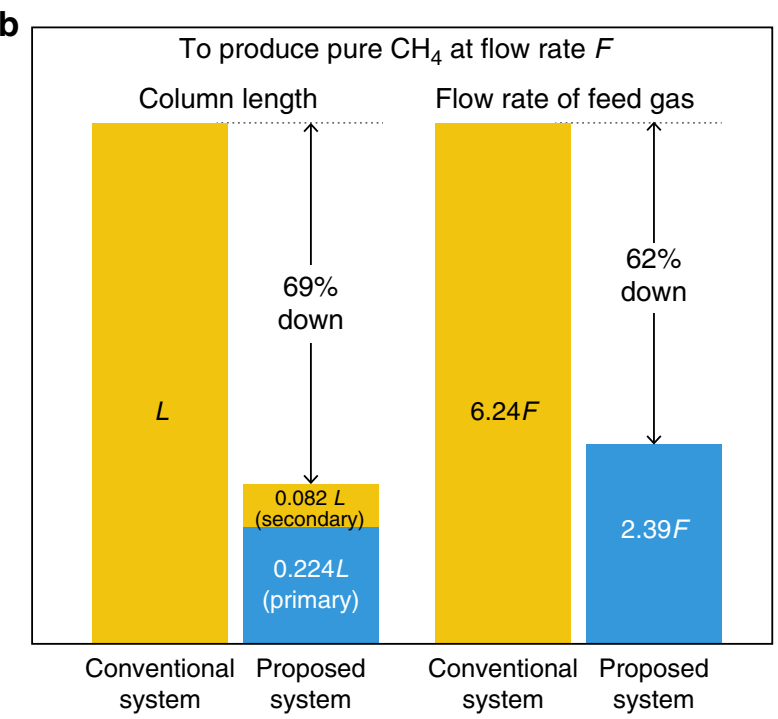

Fig. 8 Comparison between the conventional and proposed systems. a Illustrations of a conventional system using HKUST-1 and our proposed system using ELM-11 and HKUST-1. b Comparison of column length and flow rate of feed gas required to obtain the same flow rate of product $\mathrm{CH}_{4}$, $F$, for the conventional system and our proposed one.

squeezing when the host framework shrinks and returns to the closed structure.

We also found that, owing to the intrinsic thermal management capability, ELM-11 has superior properties in terms of $\mathrm{CO}_{2}$ uptake, $\mathrm{CO}_{2}$ selectivity, $\mathrm{CO}_{2}$ working capacity, and regenerability under adiabatic operating conditions compared with those of HKUST-1, although HKUST-1 has a larger $\mathrm{CO}_{2}$ capacity under isothermal conditions. This suggests that the performance of flexible MOFs on a separation process operated under an adiabatic condition as a limit of the rapid PVSA process should be evaluated not only by the adsorption isotherms, but also by the net heat of adsorption, considering the intrinsic thermal management capability.

We proposed a sequential-column system to solve the problem of the slipping-off phenomenon with flexible MOFs and demonstrated the availability of it by measuring breakthrough curves. The proposed system with ELM-11 and HKUST-1, operating under adiabatic conditions, can produce the same amount of $\mathrm{CH}_{4}$ with much smaller columns and less feed than those of the conventional single-column system using HKUST-1. It is worth noting that our proposed sequential-column system is suitable for flexible MOFs showing pressure-aided fast gating because the primary column containing a flexible MOF can be designed to treat a gas mixture with a high concentration of $\mathrm{CO}_{2}$ or a large $P-P$ gate value. The secondary column should therefore be designed to process the slipping-off $\mathrm{CO}_{2}$ and to maximize the utilization of fast gating of the flexible MOFs. Further, note that filling a simple mixture of a flexible MOF and a rigid nanoporous material into one adsorption column cannot inherently solve the slipping-off problem. Mixing the materials only produces a type IV isotherm (IUPAC classification ${ }^{38}$ ) as a sum of the gate adsorption and Langmuir-type isotherms, which cannot avoid the two-stage breakthrough of $\mathrm{CO}_{2}$, although a modest amount of pure $\mathrm{CH}_{4}$ can be obtained before the first breakthrough of $\mathrm{CO}_{2}$ (see Supplementary Fig. 5 for more details). The efficiency of the sequential-column system can be further improved if the operations for the primary column filled with a flexible MOF and the secondary column filled with a conventional adsorbent are optimized and performed individually. This is technically feasible by installing a multi-way valve at the junction of the two columns, which enables simultaneous operations of the desorption process for the primary column and purging process for the secondary column, leading to a reduction in the total cycle time (Supplementary Fig. 6). Thus, our sequential-column system can provide a variety of options for the rapid PVSA operations. Our system is also highly customizable for other separation applications because the resolution of the slipping-off problem of flexible MOFs enables effective separation of a mixture of gases, one or both of which have high added value, such as $\mathrm{C}_{3} \mathrm{H}_{6} / \mathrm{C}_{3} \mathrm{H}_{8}, \mathrm{C}_{2} \mathrm{H}_{4} / \mathrm{C}_{2} \mathrm{H}_{6}$, and $\mathrm{H}_{2} / \mathrm{CH}_{4}$. Accordingly, we believe that our methodology provides a significant advance in the field of PVSA using solid adsorbents. Moreover, we anticipate that the intrinsic thermal management and the pressure-aided fast gating capabilities of flexible MOFs will also be useful for increasing the efficiency of TSA for $\mathrm{CO}_{2}$ capture, which has been comprehensively studied by Hefti et al. ${ }^{39}$.

It should be also noted that, to realize rapid PVSA using the flexible MOFs, some issues must be resolved, for example, the hindrance of gate-opening by the pelletization of flexible MOFs, pellets braking owing to the gate-opening, and a pressure drop owing to the volume expansion of the pellets induced by the gateopening. We have already started addressing these concerns, and the results will be published elsewhere.

\section{Methods}

Rapid PVSA process for landfill gas separation. We considered the following four elementary steps for the rapid PVSA process: (i) co-current pressurization and adsorption of an equimolar $\mathrm{CO}_{2} / \mathrm{CH}_{4}$ mixture at $500 \mathrm{kPa}$, (ii) co-current depressurization and rinsing with pure $\mathrm{CO}_{2}$ at $250 \mathrm{kPa}$, (iii) counter-current desorption at $15 \mathrm{kPa}$ (a bench-scale PVSA plant for $\mathrm{CO}_{2}$ separation using $\mathrm{NaX}$ zeolite is operated at $10 \mathrm{kPa}^{40}$ ), and (iv) counter-current purging of remaining $\mathrm{CO}_{2}$ in the adsorbent with pure $\mathrm{CH}_{4}$ at $15 \mathrm{kPa}$.

For simplicity, we assumed that the heat transfer from the adsorbent to the mixture gas and the adsorption tower can be ignored, and that the heat transfer between the adsorbent crystals is sufficiently rapid, which should correspond to the conditions under rapid and adiabatic adsorption/desorption operations.

The following four factors were investigated to evaluate the $\mathrm{CO}_{2}$ separation characteristics of ELM-11 and HKUST-1:

1. $\mathrm{CO}_{2}$ uptake: $N_{\mathrm{CO}_{2}}^{\mathrm{ads}}$

2. $\mathrm{CO}_{2}$ selectivity: $S^{\mathrm{ads}}=\left(N_{\mathrm{CO}_{2}}^{\mathrm{ads}} / N_{\mathrm{CH}_{4}}^{\mathrm{ads}}\right) /\left(y_{\mathrm{CO}_{2}} / y_{\mathrm{CH}_{4}}\right)$,

3. $\mathrm{CO}_{2}$ working capacity: $\Delta N_{\mathrm{CO}_{2}}=N_{\mathrm{CO}_{2}}^{\text {ads }}-N_{\mathrm{CO}_{2}}^{\text {des }}$, and

4. regenerability: $R_{\mathrm{e}}=\Delta N_{\mathrm{CO}_{2}} / N_{\mathrm{CO}_{2}}^{\text {ads }}$,

where $N_{i}$ is the amount of component $i$ adsorbed, $y_{i}$ is the mole fraction of component $i$ in the gas phase, and superscripts 'ads' and 'des' denote adsorption and desorption operating conditions, respectively.

$\mathrm{CO}_{2}$ and $\mathrm{CH}_{\mathbf{4}}$ adsorption measurements. Pre-ELM-11 was purchased from Tokyo Chemical Industry Co. and was transformed into ELM-11 by heating at 
$373 \mathrm{~K}$ for $10 \mathrm{~h}$ under a vacuum $(<0.1 \mathrm{mPa})$. The adsorption isotherms of $\mathrm{CO}_{2}$ over the temperature range of $195-298 \mathrm{~K}$ and $\mathrm{CH}_{4}$ at $298 \mathrm{~K}$ on ELM-11 were obtained using a BELSORP-max (MicrotracBEL Co.) and a cryostat equipped with a twostage Gifford-McMahon (GM) refrigerator ${ }^{41}$. The sample cell temperature fluctuation was maintained within $\pm 0.01 \mathrm{~K}$ during the adsorption measurements.

In situ XRPD measurements. The in situ XRPD patterns of ELM-11 in vacuo and after adsorption of $\mathrm{CO}_{2}$ gas $(50 \mathrm{kPa}), \mathrm{CH}_{4}$ gas $(50 \mathrm{kPa})$, and an equimolar $\mathrm{CO}_{2} /$ $\mathrm{CH}_{4}$ mixture gas $(94 \mathrm{kPa})$ at $273 \mathrm{~K}$ were obtained using a SmartLab instrument with $\mathrm{Cu} \mathrm{Ka}$ radiation (Rigaku Co.), which has a cryostat equipped with a singlestage GM refrigerator connected to BELSORP-18 volumetric adsorption equipment (MicrotracBEL Co.). ELM-11 was transformed from pre-ELM-11 under the same conditions mentioned above, and the sample cell temperature was kept within $\pm 0.01 \mathrm{~K}$ during the XRPD measurements.

Time-resolved in situ synchrotron XRPD measurements. The pre-ELM-11 sample was placed at the end of a 0.3 -mm-diameter borosilicate glass capillary, which was attached to a stainless-steel tube with an epoxy adhesive. The sample was then evacuated for $10 \mathrm{~h}$ at $373 \mathrm{~K}$ to transform it into ELM-11. Time-resolved in situ synchrotron XRPD patterns of ELM-11 during gate adsorption of $\mathrm{CO}_{2}$ at $273 \mathrm{~K}$ were measured on the BL02B2 beamline of the SPring- 8 synchrotron facility, Japan, using a large Debye-Scherrer-type diffractometer with a multi-modular system constructed with six MYTHEN detectors ${ }^{42,43}$. The temperature of the glass capillary was controlled by a nitrogen gas blower at $273 \mathrm{~K}$, and the wavelength of the incident X-rays was $0.099899 \mathrm{~nm}$. The in situ synchrotron XRPD patterns were continuously obtained by exposing the sample for $1 \mathrm{~s}$ at regular intervals of $50 \mathrm{~ms}$. After $4.15 \mathrm{~s}$ from starting the XRPD measurements, $\mathrm{CO}_{2}$ gas at $103 \mathrm{kPa}$ filled in a gas manifold of a remote gas handling system was automatically introduced into the glass capillary in which the ELM-11 sample was maintained in a vacuum. The $\mathrm{CO}_{2}$ gas pressure was decreased to $41 \mathrm{kPa}$ within $1 \mathrm{~s}$ at the latest and the pressure was rigorously kept constant during the XRPD measurements. In the case of desorption measurement, the $\mathrm{CO}_{2}$ gas was rapidly depressed from 100 to $3.8 \mathrm{kPa}$ through a needle valve; the XRPD measurements were performed under the same conditions for the adsorption measurement. Peak intensities of the 020 reflection at $10.2^{\circ}$ for the closed phase of ELM-11 and the 002 reflection at $6.1^{\circ}$ for the open phase of ELM-11 were obtained by nonlinear least-squares fitting of the pseudoVoigt function. The fractions of each phase transformed as a function of time were determined by normalizing the peak intensities by those after completion of the transition for the open phase and before gas introduction for the closed phase. For the adsorption process, the following KJMA equation ${ }^{21,22}$ was fitted to the relation between the fraction transformed of the open phase and time:

$$
\alpha=1-\exp \left(-k t^{n}\right),
$$

where $\alpha$ is the fraction transformed at time $t, k$ is the rate constant, and $n$ is the number of dimensions in which the transition occurs. For the closed phase, the equation is arranged as

$$
\alpha=\exp \left(-k t^{n}\right) .
$$

The fitting of the KJMA equation was performed for the data after the introduction of $\mathrm{CO}_{2}$ gas.

Time-resolved in situ synchrotron XRPD measurements for the adsorption process on ELM-11 were also performed at $264 \mathrm{~K}$ for the $\mathrm{CO}_{2}$ pressure of $41.0 \mathrm{kPa}$, at $256 \mathrm{~K}$ for $40.8 \mathrm{kPa}$, at $241 \mathrm{~K}$ for $40.8 \mathrm{kPa}$, and at $227 \mathrm{~K}$ for the five constant $\mathrm{CO}_{2}$ pressures of $7.74,13.0,16.9,31.0$, and $40.8 \mathrm{kPa}$. The pressure of $\mathrm{CO}_{2}, P$, introduced into the glass capillary was controlled by preliminarily adjusting the pressure of $\mathrm{CO}_{2}$ dosed in the gas manifold of the remote gas handling system. The correlation between $k$, and the pressure difference between $P$ and the gate-opening pressure $P^{\text {gate }}$ was investigated for all the open phase data. This is formulated as follows:

$$
k(P, T)=k_{0}\left(P-P^{\text {gate }}\right),
$$

where $k_{0}$ is a constant and the gate-opening pressure at the corresponding temperature $T$ is evaluated by the relation obtained from the experimental adsorption isotherms over a wide temperature range of 195-298 K (Supplementary Fig. 7):

$$
\ln P^{\text {gate }}[\mathrm{kPa}]=-3064.5 / T[\mathrm{~K}]+14.683
$$

GCMC simulations. Adsorption isotherms of $\mathrm{CO}_{2}$ and $\mathrm{CH}_{4}$ on ELM-11 with the open framework structure were obtained using our own GCMC code. The Rietveld refined structure of ELM-11 at $298 \mathrm{~K}$, as determined in our previous work ${ }^{23}$, was used as the open framework structure. The framework atoms were fixed, and four trial moves (displacement, rotation, creation, and deletion) for $\mathrm{CO}_{2}$ and three trial moves (displacement, creation, and deletion) for $\mathrm{CH}_{4}$ were performed with the equal probabilities. The system was equilibrated at $1 \times 10^{7}$ Monte Carlo steps, after which data were collected for another $1 \times 10^{7}$ steps. The length of the Markov chain of $1 \times 10^{7}$ steps corresponds to $>6 \times 10^{4}$ trials per guest molecule. The simulation box was constructed with $3 \times 3 \times 2$ unit cells and periodic boundary conditions were applied in the $a, b$, and $c$ directions.
The guest-guest and guest-host interaction potential, $U_{\text {guest }}$, was assumed to be the sum of the Coulombic and Lennard-Jones (LJ) potentials:

$$
\begin{gathered}
U_{\text {guest }}=U_{\text {Coulombic }}+U_{\mathrm{LJ}}, \\
U_{\text {Coulombic }}=\sum \frac{q_{i} q_{j}}{4 \pi \varepsilon_{0} r_{i j}}, \\
U_{\mathrm{LJ}}=\sum 4 \varepsilon_{i j}\left[\left(\frac{\sigma_{i j}}{r_{i j}}\right)^{12}-\left(\frac{\sigma_{i j}}{r_{i j}}\right)^{6}\right],
\end{gathered}
$$

where $q_{i}$ is the atomic charge, $\varepsilon_{0}\left(8.8542 \times 10^{-12} \mathrm{C}^{2} \mathrm{~N}^{-1} \mathrm{~m}^{-2}\right)$ is the permittivity in vacuum, $r_{i j}$ is the interatomic distance, and $\sigma_{i j}$ and $\varepsilon_{i j}$ are the LJ parameters. The Ewald summation method was used to correct the long-range Coulombic interactions with a charge screening constant of $2.0 \mathrm{~nm}^{-1}$ and reciprocal space sum for $\boldsymbol{k}$ vectors of $L_{a} / 2 \pi|\boldsymbol{k}|, L_{b} / 2 \pi|\boldsymbol{k}|$, and $L_{c} / 2 \pi|\boldsymbol{k}|<10$ (where $L_{a}, L_{b}$, and $L_{c}$ are the dimensions of the simulation box). The Lorentz-Berthelot mixing rules were applied to calculate the short-range interactions and were truncated at a cutoff distance of 1.6289 and $1.5557 \mathrm{~nm}$ for $\mathrm{CO}_{2}$ and $\mathrm{CH}_{4}$, respectively. The partial atomic charges of the host framework were obtained using periodic density functional theory (DFT) calculations at the GGA-PBE/DNP level and Mulliken population analysis using the $\mathrm{DMol}^{3}$ package ${ }^{44,45}$. The universal force field (UFF) ${ }^{46}$ was applied to calculate the $\mathrm{LJ}$ interaction term of the framework atoms by modifying the energy parameters as $0.74 \varepsilon_{\mathrm{UFF}}{ }^{26}$. The atomic coordinates, charges, and $L J$ parameters of the host framework are listed in Supplementary Tables 2 and 3. The interaction parameters for $\mathrm{CO}_{2}{ }^{47}$ and $\mathrm{CH}_{4}{ }^{48}$ are listed in Supplementary Tables 4 and 5.

The adsorption isotherms for an equimolar $\mathrm{CO}_{2} / \mathrm{CH}_{4}$ gas mixture on ELM-11 were obtained by using the RASPA ${ }^{49}$ software. We used the same settings and force fields for ELM-11, $\mathrm{CO}_{2}$, and $\mathrm{CH}_{4}$, as mentioned above.

Specific heat of ELM-11 and HKUST-1. To evaluate the specific heat of ELM-11, we conducted phonon calculations for the closed and open states of ELM-11 according to the density functional perturbation theory using the VASP ${ }^{50,51}$ and PHONOPY ${ }^{52}$ codes. For the calculations using VASP, we implemented projectoraugmented wave method pseudopotentials $s^{53}$ with the GGA-PBE exchange-correlation functional and $400 \mathrm{eV}$ plane wave cutoffs. We used a $1 \times 1 \times 1$ unit cell (two primitive cells) for both the states because of the large cell size (204 and 228 atoms for the closed and open structures, respectively). The Brillouin zone of the closed state was sampled using a $3 \times 3 \times 2$ Gamma-centred Monkhorst-Pack $k$-point mesh, and that of the open state was sampled using a $2 \times 3 \times 2 k$-point mesh.

When the lattice vibrations are described by the harmonic approximation, the specific heat at constant volume, $C_{\mathrm{v}}$, can be represented as

$$
C_{\mathrm{V}}=\sum_{\mathbf{q}, \nu} k_{\mathrm{B}}\left(\frac{\hbar \omega(\mathbf{q}, \nu)}{k_{\mathrm{B}} T}\right)^{2} \frac{\exp \left(\frac{\hbar \omega(\mathbf{q}, \nu)}{k_{\mathrm{B}} T}\right)}{\left[\exp \left(\frac{\hbar \omega(\mathbf{q}, \nu)}{k_{\mathrm{B}} T}\right)-1\right]^{2}},
$$

where $\mathbf{q}$ is the wave vector, $v$ is the index for the phonon branch, $k_{\mathrm{B}}$ is the Boltzmann factor, $\hbar$ is the reduced Planck constant, $\omega$ is the vibrational frequency, and $T$ is the temperature. Here, the specific heat at constant pressure, $C_{\mathrm{p}}$, was assumed to be equal to $C_{\mathrm{v}}$ because we assumed adsorption and desorption processes under moderate temperatures. The summation for $\mathbf{q}$ and $v$ implies the addition for all the vibrational frequencies in the phonon density of states. The obtained phonon density of states and specific heat of ELM-11 as a function of temperature are shown in Supplementary Figs 8 and 9, respectively. The regular specific heat of ELM-11 in the open state at $298 \mathrm{~K}$, obtained using this calculation, was $0.94 \mathrm{~J} \mathrm{~g}^{-1} \mathrm{~K}^{-1}$

We fitted a polynomial function to the experimental specific heats of HKUST-1 reported by Kloutse et al. ${ }^{29}$ (below $320 \mathrm{~K}$ ) and $\mathrm{Mu}$ et al. ${ }^{30}$ (over $333 \mathrm{~K}$ ), and the function was integrated with respect to temperature to evaluate the heat required to change the temperature of the host framework (green plane in Fig. 5a). The parameters of the polynomial function are listed in Supplementary Table 6, and the specific heat of HKUST-1 as a function of temperature is shown in Supplementary Fig. 9. The regular specific heat of HKUST-1 at $298 \mathrm{~K}$ was $0.78 \mathrm{Jg}^{-1} \mathrm{~K}^{-1}$.

Transition enthalpy and thermal management capability. The transition enthalpy during gate adsorption, required in order to assess the intrinsic thermal management capability, is expressed as: ${ }^{13}$

$$
\Delta H^{\text {trs }}=\Delta H^{\text {host }}+\Delta H^{\text {guest }}\left(P^{\text {gate }}\right)=\Delta H^{\text {host }}-N_{\mathrm{op}}^{\text {guest }}\left(P^{\text {gate }}\right) q_{\mathrm{op}}^{\text {int }}\left(P^{\text {gate }}\right),
$$

where $\Delta H^{\text {host }}$ and $\Delta H^{\text {guest }}\left(P^{\text {gate }}\right)$ are the enthalpy changes of the host and guest during gate adsorption, and $N_{\mathrm{op}}^{\text {guest }}\left(P^{\text {gate }}\right)$ and $q_{\mathrm{op}}^{\text {int }}\left(P^{\text {gate }}\right)$ are the amount of gas adsorbed on the open framework and the molar integral heat at the gate pressure $P$ gate, respectively. Here, the enthalpies are given as values per weight of adsorbent. $q_{\mathrm{op}}^{\text {int }}$ is positive when heat is released from the system. When the pressure is increased to $P$ after the gate-opening at $P$ gate and additional guest adsorption occurs without host deformation, the heat of adsorption, $q^{\text {add }}$, is released from 
the system:

$$
q^{\text {add }}(P)=N_{\text {op }}^{\text {guest }}(P) q_{\text {op }}^{\text {int }}(P)-N_{\text {op }}^{\text {guest }}\left(P^{\text {gate }}\right) q_{\text {op }}^{\text {int }}\left(P^{\text {gate }}\right) .
$$

Hence, the net heat, $q^{\text {net }}$, released by the adsorption through the gate-opening at $P\left(>P^{\text {gate }}\right)$ is written as

$$
q^{\text {net }}(P)=-\Delta H^{\text {trs }}+q^{\text {add }}(P)=N_{\mathrm{op}}^{\text {guest }}(P) q_{\mathrm{op}}^{\text {int }}(P)-\Delta H^{\text {host }} .
$$

$q_{\mathrm{op}}^{\text {int }}(P)$ can be evaluated using the following equation:

$$
q_{\mathrm{op}}^{\text {int }}(P)=-\frac{H_{\mathrm{op}}^{\text {guest }}(P)-H^{\text {gas }}(P)}{N_{\mathrm{op}}^{\text {guest }}(P)} \approx u_{\mathrm{op}}^{\text {guest }}(P)+R T,
$$

where $H_{\mathrm{op}}^{\text {guest }}(P)-H^{\text {gas }}(P)$ is the enthalpy change when $N_{\mathrm{op}}^{\text {guest }}(P)$ of the gas molecules are encapsulated in the open framework, $u_{\mathrm{op}}^{\text {guest }}(P)$ is the molar interaction potential energy of the guest molecules, $R$ is the gas constant, and $T$ is the temperature. We performed GCMC simulations for the open framework to obtain the values of $N_{\mathrm{op}}^{\text {guest }}(P)$ and $u_{\mathrm{op}}^{\text {guest }}(P)$. We then assumed $\Delta H^{\text {host }}=\Delta U^{\text {host }}+$ $P \Delta V \approx \Delta U^{\text {host }}$, where $\Delta V$ is the volume change of the host and $\Delta U^{\text {host }}$ is the internal energy change of the host because the $P \Delta V$ term is negligible compared to $\Delta U^{\text {host }}$ in most cases. We define the intrinsic thermal management capability, $e$, as

$$
e=\frac{\Delta H^{\text {guest }}(P)-q^{\text {net }}(P)}{\Delta H^{\text {guest }}(P)},
$$

which represents the ratio of the endothermic heat caused by host deformation to the total exothermic heat resulting from guest desorption.

Adsorption amounts and heat of adsorption on HKUST-1. The amounts of $\mathrm{CO}_{2}$ and $\mathrm{CH}_{4}$ adsorbed on HKUST-1 were evaluated using the Virial-Langmuir equation reported by Chowdhury et al. ${ }^{24}$ :

$$
\begin{aligned}
f & =\frac{n^{\max }(T) n(f, T)}{\beta(T)\left\{n^{\max }(T)-n(f, T)\right\}} \exp \left\{b(T) n(f, T)+c(T) n(f, T)^{2}\right\} \\
n^{\max }(T) & =\eta_{0}+\frac{\eta_{1}}{T} \\
\beta(T) & =\beta_{0} \exp \left(\frac{\beta_{1}}{T}\right) \\
b(T) & =b_{0}+\frac{b_{1}}{T} \\
c(T) & =c_{0}+\frac{c_{1}}{T},
\end{aligned}
$$

where $f$ is the fugacity, $n$ is the amount adsorbed, and $\eta_{i}, \beta_{i}, b_{i}$, and $c_{i}(i=0,1)$ are parameters that are listed in Supplementary Table 7 . We assumed that the fugacity can be replaced by the pressure of a real gas because we treat the adsorption and desorption processes only under moderate pressures and temperatures. The isosteric heat of adsorption, $q^{\text {st }}$, can be obtained by substituting Eq. (14) into the Clausius-Clapeyron equation:

$$
\begin{aligned}
-\frac{q^{\mathrm{st}}(n, T)}{R} & =\left(\frac{\partial \ln P}{\partial(1 / T)}\right)_{n} \\
& =-\beta_{1}+b_{1} n(T)+c_{1} n(T)^{2}+\frac{\eta_{1}}{n^{\max }(T)}-\frac{\eta_{1}}{n^{\max }(T)-n(T)} .
\end{aligned}
$$

The total heat of adsorption $Q$, as depicted in Fig. 5a, was obtained using

$$
Q=\int_{0}^{n_{\mathrm{CO}_{2}}} q_{\mathrm{CO}_{2}}^{\mathrm{st}} \mathrm{d} n_{\mathrm{CO}_{2}}+\int_{0}^{n_{\mathrm{CH}_{4}}} q_{\mathrm{CH}_{4}}^{\mathrm{st}} \mathrm{d} n_{\mathrm{CH}_{4}} \text {. }
$$

Adsorption isobars and heat of adsorption on ELM-11. It has been reported that the logarithms of the gate opening and closing pressures of flexible MOFs should be proportional to the reciprocal temperature ${ }^{54}$, and we confirmed that the gate opening and closing pressures of $\mathrm{CO}_{2}$ on ELM-11 also followed the relationship shown in Supplementary Fig. 7. Therefore, by using the $\ln P^{\text {gate }}$ vs reciprocal temperature plot, we evaluated the theoretical adsorption isobars and heats of adsorption on ELM-11 for an equimolar $\mathrm{CO}_{2} / \mathrm{CH}_{4}$ gas mixture at $500 \mathrm{kPa}$, pure $\mathrm{CO}_{2}$ at $250 \mathrm{kPa}$, pure $\mathrm{CO}_{2}$ at $15 \mathrm{kPa}$, and pure $\mathrm{CH}_{4}$ at $15 \mathrm{kPa}$, which correspond to the operating pressures used for the adsorption, rinsing, desorption, and purging processes, respectively. First, we determined the gate-opening/-closing temperatures of ELM-11 for pure $\mathrm{CO}_{2}$ as $335 \mathrm{~K} / 341 \mathrm{~K}$ at $250 \mathrm{kPa}$ and $256 \mathrm{~K} / 262 \mathrm{~K}$ at $15 \mathrm{kPa}$, respectively, from Supplementary Fig. 7. Then, we assumed that the gate-opening/-closing temperatures for the equimolar $\mathrm{CO}_{2} / \mathrm{CH}_{4}$ gas mixture at $500 \mathrm{kPa}$ were the same as those for pure $\mathrm{CO}_{2}$ at $250 \mathrm{kPa}$, which was based on the fact that the molar fraction of slipping-off $\mathrm{CO}_{2}$ could be predicted using the gate-opening pressure for pure $\mathrm{CO}_{2}$, as shown in Fig. $6 \mathrm{c}$. Finally, we calculated the adsorption amounts of $\mathrm{CO}_{2}$ and $\mathrm{CH}_{4}$ on the open framework structure of ELM-11 and the corresponding heats of adsorption at temperatures below the gate-opening temperature using the GCMC simulations. The adsorption loadings of $\mathrm{CO}_{2}$ and $\mathrm{CH}_{4}$ and the corresponding heats of adsorption at temperatures above the gate-opening temperature were set to be zero because the closed framework structure showed no adsorption of $\mathrm{CO}_{2}$ and $\mathrm{CH}_{4}$.
Breakthrough curve measurement. Breakthrough curves were measured using labmade equipment consisting of three mass-flow controllers (HORIBA STEC Co.), a static gas mixer, a $\varnothing 9 \mathrm{~mm}$ glass tube as the primary column, a $\varnothing 6 \mathrm{~mm}$ glass tube as the secondary column, a bypass flow path, a back-pressure regulator, and a quadrupole mass spectrometer (CANON ANELVA Co.). The flowsheet of the apparatus is illustrated in Supplementary Fig. 10. The pre-ELM-11 sample used in this experiment was synthesized using the protocol reported by Kondo et al. ${ }^{16}$ after modification: a methanol solution of $4,4^{\prime}$-bipyridine $(1.60 \mathrm{M}, 365 \mathrm{~mL})$ was added to a water $(200 \mathrm{~mL})$ methanol $(92 \mathrm{~mL})$ mixed solution of $\mathrm{Cu}$ (II) tetrafluoroborate $(1.00 \mathrm{M})$ for $2 \mathrm{~h}$ with vigorous stirring at room temperature. After additional stirring $(1 \mathrm{~h})$, the reaction mixture was filtrated, and the filter cake was washed with water three times. The blue powder was dried at room temperature under a vacuum below $5 \mathrm{mPa}$ for $12 \mathrm{~h}$. HKUST-1 (BasoliteC 300) was purchased from Sigma-Aldrich. Pre-ELM-11 and HKUST-1 were placed in the adsorption columns and activated by heating at $393 \mathrm{~K}$ for $12 \mathrm{~h}$ under a vacuum $(<0.1 \mathrm{mPa})$. The adsorption columns were then purged with $200 \mathrm{kPa}$ of pure Ar and kept at $273 \mathrm{~K}$ using a thermostatic bath. Next, an equimolar $\mathrm{CO}_{2} / \mathrm{CH}_{4}$ gas mixture was flowed through the bypass flow path. Its flow rate was controlled to be $20 \mathrm{sccm}$ (standard $\mathrm{cm}^{3} \mathrm{~min}^{-1}$ ) by the mass-flow controllers, and the system pressure was maintained at $200 \mathrm{kPa}$ by the back-pressure regulator. Then, the feed stream was switched from the bypass channel to the adsorption columns side, and the gas composition downstream of the back-pressure regulator was measured using the mass spectrometer, which was calibrated using certified $\mathrm{CO}_{2} / \mathrm{CH}_{4} / \mathrm{Ar}$ gas mixtures before measuring the breakthrough curves.

Material balance calculations for column systems. We evaluated the column length and molar flow rate of the feed gas required to obtain the same molar flow rate of $\mathrm{CH}_{4}$ for conventional and sequential-column systems, including case I and case II, via material balance calculations. The details of the material balance calculations are provided in the Supplementary Method.

\section{Data availability}

The data that support the findings of this study are provided in Supplementary Information and the online repository at https://github.com/2koza/slipping-off. They can also be available from the corresponding author upon request.

\section{Code availability}

The codes used in this study are available from the corresponding author upon reasonable request.

Received: 3 October 2018; Accepted: 6 July 2020;

Published online: 03 August 2020

\section{References}

1. Sholl, D. S. \& Lively, R. P. Seven chemical separations to change the world. Nature 532, 435-437 (2016).

2. Lopes, F. V. S., Grande, C. A. \& Rodrigues, A. E. Fast-cycling VPSA for hydrogen purification. Fuel 93, 510-523 (2012).

3. Sircar, S. \& Hanley, B. F. Production of oxygen enriched air by rapid pressure swing adsorption. Adsorption 1, 313-320 (1995).

4. Chai, S. W., Kothare, M. V. \& Sircar, S. Rapid pressure swing adsorption for reduction of bed size factor of a medical oxygen concentrator. Ind. Eng. Chem. Res. 50, 8703-8710 (2011)

5. Horstmeier, J. F., Gomez Lopez, A. \& Agar, D. W. Performance improvement of vacuum swing adsorption processes for $\mathrm{CO}_{2}$ removal with integrated phase change material. Int. J. Greenh. Gas. Con. 47, 364-375 (2016).

6. Schneemann, A. et al. Flexible metal-organic frameworks. Chem. Soc. Rev. 43, 6062-6096 (2014).

7. Horike, S., Shimomura, S. \& Kitagawa, S. Soft porous crystals. Nat. Chem. 1, 695-704 (2009).

8. Fairen-Jimenez, D. et al. Opening the gate: framework flexibility in ZIF-8 explored by experiments and simulations. J. Am. Chem. Soc. 133, 8900-8902 (2011)

9. Coudert, F.-X., Boutin, A., Fuchs, A. H. \& Neimark, A. V. Adsorption deformation and structural transitions in metal-organic frameworks: from the unit cell to the crystal. J. Phys. Chem. Lett. 4, 3198-3205 (2013).

10. Krause, S. et al. A pressure-amplifying framework material with negative gas adsorption transitions. Nature 532, 348-352 (2016)

11. Verploegh, R. J., Nair, S. \& Sholl, D. S. Temperature and loading-dependent diffusion of light hydrocarbons in ZIF-8 as predicted through fully flexible molecular simulations. J. Am. Chem. Soc. 137, 15760-15771 (2015).

12. Mason, J. A. et al. Methane storage in flexible metal-organic frameworks with intrinsic thermal management. Nature 527, 357-361 (2015).

13. Hiraide, S., Tanaka, H., Ishikawa, N. \& Miyahara, M. T. Intrinsic thermal management capabilities of flexible metal-organic frameworks for carbon dioxide separation and capture. ACS Appl. Mater. Interfaces 9, 41066-41077 (2017). 
14. Horike, S., Inubushi, Y., Hori, T., Fukushima, T. \& Kitagawa, S. A solid solution approach to $2 \mathrm{D}$ coordination polymers for $\mathrm{CH}_{4} / \mathrm{CO}_{2}$ and $\mathrm{CH}_{4} / \mathrm{C}_{2} \mathrm{H}_{6}$ gas separation: equilibrium and kinetic studies. Chem. Sci. 3, 116-120 (2012).

15. Li, D. \& Kaneko, K. Hydrogen bond-regulated microporous nature of copper complex-assembled microcrystals. Chem. Phys. Lett. 335, 50-56 (2001).

16. Kondo, A. et al. Novel expansion/shrinkage modulation of $2 \mathrm{D}$ layered MOF triggered by clathrate formation with $\mathrm{CO}_{2}$ molecules. Nano Lett. 6, 2581-2584 (2006).

17. Bae, Y. S. \& Snurr, R. Q. Development and evaluation of porous materials for carbon dioxide separation and capture. Angew. Chem. Int. Ed. 50, 11586-11596 (2011).

18. Kenarsari, S. D. et al. Review of recent advances in carbon dioxide separation and capture. RSC Adv. 3, 22739 (2013).

19. Choi, S., Drese, J. H. \& Jones, C. W. Adsorbent materials for carbon dioxide capture from large anthropogenic point sources. ChemSusChem 2, 796-854 (2009).

20. Chui, S. S. A chemically functionalizable nanoporous material $\left[\mathrm{Cu}_{3}(\mathrm{TMA})_{2}\left(\mathrm{H}_{2} \mathrm{O}\right)_{3}\right]_{\mathrm{n}}$. Science 283, 1148-1150 (1999).

21. De Bruijn, T. J. W., De Jong, W. A. \& Van Den Berg, P. J. Kinetic parameters in Avrami-Erofeev type reactions from isothermal and non-isothermal experiments. Thermochim. Acta 45, 315-325 (1981).

22. Krüger, P. On the relation between non-isothermal and isothermal Kolmogorov-Johnson-Mehl-Avrami crystallization kinetics. J. Phys. Chem. Solids 54, 1549-1555 (1993).

23. Hiraide, S., Tanaka, H. \& Miyahara, M. T. Understanding gate adsorption behaviour of $\mathrm{CO}_{2}$ on elastic layer-structured metal-organic framework-11. Dalton Trans. 45, 4193-4202 (2016).

24. Chowdhury, P., Mekala, S., Dreisbach, F. \& Gumma, S. Adsorption of CO, $\mathrm{CO}_{2}$ and $\mathrm{CH}_{4}$ on $\mathrm{Cu}-\mathrm{BTC}$ and MIL-101 metal organic frameworks: Effect of open metal sites and adsorbate polarity. Micropor. Mesopor. Mater. 152, 246-252 (2012).

25. Myers, A. L. \& Prausnitz, J. M. Thermodynamics of mixed-gas adsorption. AlChE J. 11, 121-127 (1965).

26. Tanaka, H., Hiraide, S., Kondo, A. \& Miyahara, M. T. Modeling and visualization of $\mathrm{CO}_{2}$ adsorption on elastic layer-structured metal-organic framework-11: Toward a better understanding of gate adsorption behavior. $J$. Phys. Chem. C. 119, 11533-11543 (2015).

27. D'Alessandro, D. M., Smit, B. \& Long, J. R. Carbon dioxide capture: prospects for new materials. Angew. Chem. Int. Ed. 49, 6058-6082 (2010).

28. Pirngruber, G. D. et al. A method for screening the potential of $\mathrm{MOF}$ as $\mathrm{CO}_{2}$ adsorbents in pressure swing adsorption processes. ChemSusChem 5, 762-776 (2012).

29. Kloutse, F. A., Zacharia, R., Cossement, D. \& Chahine, R. Specific heat capacities of MOF-5, Cu-BTC, Fe-BTC, MOF-177 and MIL-53 (Al) over wide temperature ranges: Measurements and application of empirical group contribution method. Micropor. Mesopor. Mater. 217, 1-5 (2015).

30. Mu, B. \& Walton, K. S. Thermal analysis and heat capacity study of metalorganic frameworks. J. Phys. Chem. C. 115, 22748-22754 (2011).

31. Farooq, S., Hassan, M. M. \& Ruthven, D. M. Heat effects in pressure swing adsorption systems. Chem. Eng. Sci. 43, 1017-1031 (1988).

32. Tomomura, M., Nogita, S. \& Someya, K. Carbon dioxide removal from compressed air by pressure swing adsorption. Kagaku Kogaku Ronbunshu 13, 139-144 (1987).

33. Wilson, S. J. \& Webley, P. A. Cyclic steady-state axial temperature profiles in multilayer, bulk gas PSA - the case of oxygen VSA. Ind. Eng. Chem. Res. 41, 2753-2765 (2002).

34. Sotomayor, F. J. \& Lastoskie, C. M. Predicting the breakthrough performance of gating adsorbents using osmotic framework-adsorbed solution theory. Langmuir 33, 11670-11678 (2017).

35. Yang, S.-I., Choi, D.-Y., Jang, S.-C., Kim, S.-H. \& Choi, D.-K. Hydrogen separation by multi-bed pressure swing adsorption of synthesis gas. Adsorption 14, 583-590 (2008).

36. Maring, B. J. \& Webley, P. A. A new simplified pressure/vacuum swing adsorption model for rapid adsorbent screening for $\mathrm{CO}_{2}$ capture applications. Int. J. Greenh. Gas. Con 15, 16-31 (2013).

37. Yamazaki, T., Takahashi, Y. \& Yoshida, D. Adsorption of several gases on flexible metal organic framework $\left[\mathrm{Cu}(\mathrm{dhbc})_{2}\left(4,4^{\prime}-\mathrm{bpy}\right)\right] \cdot \mathrm{H}_{2} \mathrm{O}$. J. Colloid Interface Sci. 362, 463-469 (2013).

38. Thommes, M. et al. Physisorption of gases, with special reference to the evaluation of surface area and pore size distribution (IUPAC technical report). Pure Appl. Chem. 87, 1051 (2015).

39. Hefti, M., Joss, L., Bjelobrk, Z. \& Mazzotti, M. On the potential of phasechange adsorbents for $\mathrm{CO}_{2}$ capture by temperature swing adsorption. Faraday Discuss. 192, 153-179 (2016).

40. Saima, W. H., Mogi, Y. \& Haraoka, T. Development of PSA system for the recovery of carbon dioxide and carbon monoxide from blast furnace gas in steel works. Energy Procedia 37, 7152-7159 (2013).

41. Tanaka, H. et al. Adsorption-induced structural transition of ZIF-8: a combined experimental and simulation study. J. Phys. Chem. C. 118, 8445-8454 (2014).
42. Kawaguchi, S. et al. High-throughput powder diffraction measurement system consisting of multiple MYTHEN detectors at beamline BL02B2 of SPring- 8 . Rev. Sci. Instrum. 88, 085111 (2017).

43. Kawaguchi, S. et al. Fast continuous measurement of synchrotron powder diffraction synchronized with controlling gas and vapour pressures at beamline BL02B2 of SPring-8. J. Synchrotron Rad. 27, 616-624 (2020).

44. Delley, B. An all-electron numerical method for solving the local density functional for polyatomic molecules. J. Chem. Phys. 92, 508-517 (1990).

45. Delley, B. From molecules to solids with the $\mathrm{DMol}^{3}$ approach. J. Chem. Phys. 113, 7756-7764 (2000).

46. Rappé, A. K., Casewit, C. J., Colwell, K. S., Goddard, W. A. III \& Skiff, W. M. UFF, a full periodic table force field for momechanics and molecular dynamics simulations. J. Am. Chem. Soc. 114, 10024-10035 (1992).

47. Chen, Y. F., Lee, J. Y., Babarao, R., Li, J. \& Jiang, J. W. A highly hydrophobic metal-organic framework $\mathrm{Zn}(\mathrm{BDC})(\mathrm{TED})_{0.5}$ for adsorption and separation of $\mathrm{CH}_{3} \mathrm{OH} / \mathrm{H}_{2} \mathrm{O}$ and $\mathrm{CO}_{2} / \mathrm{CH}_{4}$ : an integrated experimental and simulation study. J. Phys. Chem. C. 114, 6602-6609 (2010).

48. Cracknell, R. F. \& Nicholson, D. Adsorption and selectivity of carbon dioxide with methane and nitrogen in slit-shaped carbonaceous micropores: simulation and experiment. Adsorption 2, 193-203 (1996).

49. Dubbeldam, D., Calero, S., Ellis, D. E. \& Snurr, R. Q. RASPA: molecular simulation software for adsorption and diffusion in flexible nanoporous materials. Mol. Simul. 42, 81-101 (2016).

50. Kresse, G. \& Furthmüller, J. Efficiency of ab-initio total energy calculations for metals and semiconductors using a plane-wave basis set. Comput. Mater. Sci. 6, 15-50 (1996).

51. Kresse, G. \& Furthmüller, J. Efficient iterative schemes for ab initio totalenergy calculations using a plane-wave basis set. Phys. Rev. B 54, 11169-11186 (1996).

52. Togo, A. \& Tanaka, I. First principles phonon calculations in materials science. Scr. Mater. 108, 1-5 (2015).

53. Blöchl, P. E. Projector augmented-wave method. Phys. Rev. B 50, 17953-17979 (1994).

54. Numaguchi, R., Tanaka, H., Watanabe, S. \& Miyahara, M. T. Simulation study for adsorption-induced structural transition in stacked-layer porous coordination polymers: equilibrium and hysteretic adsorption behaviors. J. Chem. Phys. 138, 054708 (2013).

\section{Acknowledgements}

This work was financially supported by a Grant-in-Aid for JSPS fellows no. 15J05846, a Grant-in-Aid for Research Activity Start-up no. 19K23574, a Grant-in-Aid for Scientific Research (B) no. 17H03097 and no. 20H04466, a Challenging Research (Exploratory) no. 18K18975, the ENEOS Hydrogen Trust Fund, JST CREST grant no. JPMJCR1324, Japan and "Five-star Alliance" in "NJRC Mater. \& Dev.". For this work, we used the supercomputer at ACCMS, Kyoto University. We thank Dr. Atsushi Kondo and professor Hirofumi Kanoh for fruitful discussions. The synchrotron radiation experiments were performed at the BL02B2 beamline of SPring- 8 with the approval of the Japan Synchrotron Radiation Research Institute (JASRI) (proposal no. 2017B1210, 2018A1082, 2018B1539, 2019B1290).

\section{Author contributions}

S.H., H.T., H.K., and M.T.M. designed this study and wrote the paper. S.H. performed the in situ XRPD experiments, the adsorption measurements, and the calculations. H.T. S.K., and Y.S. performed time-resolved in situ synchrotron XRPD measurements. H.K. synthesized ELM-11 to measure the breakthrough curves, and S.H. and Y.S. performed these measurements. All authors discussed the results and commented on the manuscript.

\section{Competing interests}

The authors declare no competing interests.

\section{Additional information}

Supplementary information is available for this paper at https://doi.org/10.1038/s41467 020-17625-3.

Correspondence and requests for materials should be addressed to M.T.M. or H.T.

Peer review information Nature Communications thanks François-Xavier Coudert, Carlos Grande, and Krishna Chandran Jayachandrababu for their contributions to the peer review of this work. Peer review reports are available.

Reprints and permission information is available at http://www.nature.com/reprints

Publisher's note Springer Nature remains neutral with regard to jurisdictional claims in published maps and institutional affiliations. 
(c) (i) Open Access This article is licensed under a Creative Commons Attribution 4.0 International License, which permits use, sharing, adaptation, distribution and reproduction in any medium or format, as long as you give appropriate credit to the original author(s) and the source, provide a link to the Creative Commons license, and indicate if changes were made. The images or other third party material in this article are included in the article's Creative Commons license, unless indicated otherwise in a credit line to the material. If material is not included in the article's Creative Commons license and your intended use is not permitted by statutory regulation or exceeds the permitted use, you will need to obtain permission directly from the copyright holder. To view a copy of this license, visit http://creativecommons.org/ licenses/by/4.0/.

(C) The Author(s) 2020 